\title{
Universiteit Utrecht
}

Pre-print provided by the author(s) and Universiteit Utrecht in accordance with publisher policies. Please cite the published version when available.

\begin{tabular}{|l|l|}
\hline Title & $\begin{array}{l}\text { Operational flexibility and economics of power plants } \\
\text { in future low-carbon power systems }\end{array}$ \\
\hline Authors & $\begin{array}{l}\text { Anne Sjoerd Brouwer, Machteld van den Broek, Ad } \\
\text { Seebregts, André Faaij }\end{array}$ \\
\hline Publication Date & $10-07-2015$ \\
\hline $\begin{array}{l}\text { Publication } \\
\text { information }\end{array}$ & Applied Energy, 156: 107-128 \\
\hline Publisher & Elsevier \\
\hline Rights & $\begin{array}{l}\text { This is the pre-print version of the following article: } \\
\text { Anne Sjoerd Brouwer, Machteld van den Broek, Ad } \\
\text { Seebregts, André Faaij. (2015) Applied Energy, volume } \\
156, \text { pp. 107 - 128 }\end{array}$ \\
\hline DOI & doi:10.1016/j.apenergy.2015.06.065 \\
\hline
\end{tabular}

(C) 2015. This manuscript version is made available under the CC-BY-NC-ND 4.0 license http://creativecommons.org/licenses/by-nc-nd/4.0/

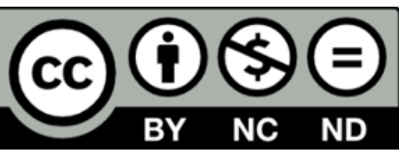




\title{
The technical, economic and flexibility performance of power plants with carbon capture in future power systems
}

\author{
Anne Sjoerd Brouwer* ${ }^{\mathrm{a}, \mathrm{b}}$, Machteld van den Broek ${ }^{\mathrm{a}}$, Ad Seebregts ${ }^{\mathrm{b}}$ and André Faaij ${ }^{\mathrm{a}, \mathrm{c}}$ \\ a Copernicus Institute for Sustainable Development, Utrecht University, Heidelberglaan 2, Utrecht, the Netherlands \\ b Energy research Centre of the Netherlands (ECN), Radarweg 60, Amsterdam, the Netherlands \\ c Energy Sustainability Research Institute Groningen, University of Groningen, Nijenborgh 4, Groningen, the Netherlands \\ * Corresponding author. a.s.brouwer@uu.nl Heidelberglaan 2, 3584CS Utrecht, the Netherlands
}

\begin{abstract}
Future power systems will require large shares of low-carbon generators such as renewables and power plants with CCS to keep global warming below 2 degrees Celsius. Intermittent renewables increase the system-wide demand for flexibility and affect the operation of thermal power plants. To further investigate the technical and economic feasibility of future power systems, a modeling toolbox was developed. It consists of a soft-linked power system optimization model (MARKAL-NL-UU) and an hourly power system simulation model (REPOWERS) that explicitly accounts for flexibility parameters based on a comprehensive literature review. With this toolbox, the technical and economic performance of power plants with Carbon Capture and Storage (CCS) is explored for four future scenarios. We find that future low-carbon power systems will have large shares of intermittent renewable sources (19-42\%) and generators with CCS (23-64\% of power generated), as their flexibility is not affected by the capture unit. The $0.6-1.6 \%$ efficiency reductions of thermal power plants are mainly driven by variability in load and exchange flows, and to a lesser extent by intermittent renewables. Economic analysis shows that the low-carbon scenarios are on average $17 \%$ $( \pm 15 \%)$ more expensive per MWh generated than the baseline scenario. Moreover, the current energy-based market model generates insufficient revenues: the price received per MWh covers only $84 \%( \pm 30 \%)$ of the total generation costs per MWh. This will reduce new investments in generation capacity and reduce power system adequacy. New or additional market designs are required to ensure sufficient in future low-carbon power systems.
\end{abstract}

Keywords: Carbon Capture and Storage, Thermal Power Plants, Flexibility, Renewable Energy, Power System Modeling.

Highlights:

- We designed a model toolbox with a soft-linked optimization and a simulation model;

- The future techno-economic \& flexibility performance of CCS generators is studied;

- Renewables are not the main driver of thermal power plant efficiency reductions;

- The current market design only covers $84 \%( \pm 30 \%)$ of total power costs per $\mathrm{MWh}$;

- Thus, new (e.g. capacity-) market designs are needed to warrant future investments.

\section{Abbreviations}

ASU - Air Separation Unit

CF - Capacity factor

CCS - Carbon Capture and Storage

ECF - European Climate Foundation

HRSG - Hear Recovery Steam Generator

IGCC - Integrated Gasification Combined Cycle

IRES - Intermittent Renewable Energy Sources

GT - Gas Turbine
LHV - Lower Heating Value

NGCC - Natural Gas Combined Cycle

PBT - Pay Back Time

PC - Pulverized Coal

PV - Photovoltaic

RES - Renewable Energy Sources

SR - Spinning Reserve

SRP - Short Run Profit 


\section{Introduction}

In order to mitigate the adverse effects of climate change, the European Commission has proposed to deeply reduce European Union greenhouse gas emissions by $40-44 \%$ by 2030 and $80-95 \%$ by 2050 compared to 1990 [1,2]. The largest emission reductions are projected for the power sector: reductions of $54-68 \%$ by 2030 and $93-99 \%$ by 2050 compared to 2050 [1]. The transition to such low-carbon power systems will significantly change the main constituents of the plant mix to low-carbon generators such as installations based on renewable energy sources (RES), nuclear power plants and generators with carbon capture and storage (CCS) [3-5].

The new low-carbon generator mix may affect the technical and economic workings of the power system. From a technical perspective, the system could run out of flexibility: intermittent RES require flexibility from the power system, whilst coal fired power plants (which are likely candidates for CCS), and nuclear power plants are relatively inflexible [6,7]. Moreover, intermittent RES may slightly reduce the efficiency of power plants [8]. From an economic perspective, intermittent RES may reduce the profitability of nuclear plants and generators with CCS by decreasing their capacity factor and lowering wholesale electricity prices. Moreover, the profit of these thermal power generators is reduced as expensive generators are pushed out of the merit order, and the generators will have to deliver more reserve capacity. As stated by the IPCC SRREN report: "combined integration of IRES and IGCC/CCS or nuclear may pose special integration challenges" [9].

Relatively few studies have specifically considered the functioning of future low-carbon power systems. In fact, an IEA report on integrating IRES into power systems observed a knowledge gap relating to the application of power plants with CCS in a power system with large amounts of IRES. Specifically, they requested more research on "Evaluation of the cost effectiveness of flexible power generation with and without CCS in future power markets." Moreover, they request "Quantification of revenue streams by regional modeling and scenario analysis of future power systems." [10].

Five identified studies have studied low-carbon energy systems with flexibility constraints of 2030 and beyond. Two studies considered the future EU energy system at large. The Roadmap 2050 study by the European Climate

Foundation (ECF) found that "Capacity factors of nuclear and coal plus CCS remain high throughout the year", and that reduced generator flexibility has small impacts, but without providing details about power system operation [3]. The European Commission ordered a study on low-carbon energy scenarios for the EU, but it does not specifically mention flexibility constraints, and only reports aggregated outcomes [4]. Bertsch et al. studied a future European low-carbon power system with a $80 \%$ RES penetration by 2050 . They concluded that flexibility will largely be provided by gas turbines, and that operation of nuclear power and generators with CCS will break-even [11,12]. Cohen studied the operation of power plants with CCS in detail for the Texas power system, but only considered wind penetrations up to $20 \%$ [13]. Hundt et al. studied the effect of nuclear power plant lifetime extension on the 2030 German power system with 40-50\% RES, without accounting for CCS [14]. Lastly, a number of studies have investigated the role of CCS in future power systems with less detailed power system models, which have lengthy time slices ( $>1$ day) and do not account for flexibility constraints [e.g. 14,15].

None of these studies specifically addressed the research requests of the IEA [10]: they did not compare the profitability of power plants with and without carbon capture, and they have not considered fundamentally different scenarios: high levels of RES are commonly assumed as a starting point. Moreover, it is often unclear how flexibility constraints were accounted for. More research is therefore needed on the combined operation of low-carbon thermal power generators in future power systems.

This study addresses these research gaps by answering the main question "How do power plants with CCS perform from a technical and an economic perspective in future low-carbon electricity systems with large shares of intermittent renewable sources, and how do they affect the flexibility of these systems?" This study distinguishes itself by introducing a novel modeling toolbox, which consists of a soft-linkage of a power system optimization model (MARKAL-NL-UU) and a power system simulation model (REPOWERS). This toolbox can simulate consistent future power system scenarios to gain insight in the transition to future low-carbon power systems. 


\section{Methodology}

A novel modeling toolbox is used to simulate the dispatch of different power plant types with CCS in the Dutch power sector for four electricity mix scenarios. The toolbox is based on a two-step approach, as shown in Figure 1. First, future power plant portfolios and $\mathrm{CO}_{2}$ prices are calculated with the MARKAL-NL-UU optimization model for each scenario, whilst optimizing for the lowest cost. Next, the generator portfolios are simulated in more detail with the REPOWERS unit commitment and economic dispatch power system model, which accounts for flexibility constraints. In the post analysis step, the outcomes of the two models are compared to check if they are internally consistent, and performance parameters are calculated.

The study focusses on the Netherlands, because it has a diverse, modern power system with the potential for large shares of IRES, and modern coal fired power plants that can be equipped with CCS [17]. In this study, the REPOWERS model is run for the years 2030 and 2050.

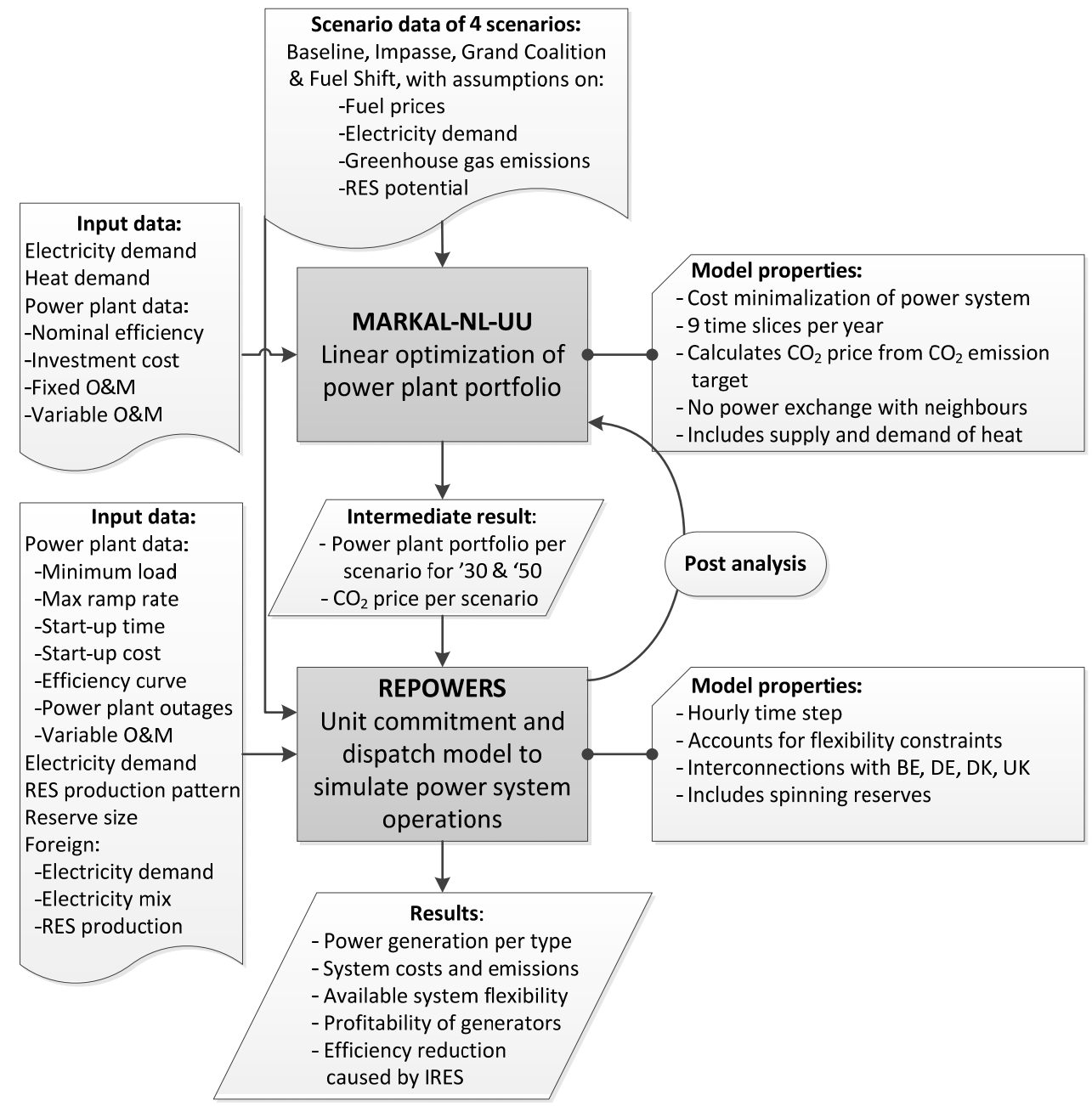

Figure 1: Schematic overview of modeling toolbox used in this study

\section{MARKAL model}

The MARKAL (MARKet ALlocation) model is a bottom-up linear optimization tool [Appendix A]. It calculates the optimal (least-cost) way to supply energy services based on available resources and a portfolio of energy conversion technologies [18,19]. The MARKAL-NL-UU model optimizes the Dutch energy system, as described in [20-22], and specifically the Dutch power sector in this study. A wide range of centralized and decentralized generation 
technologies are represented in the model. A coherent input dataset was constructed based on public sources [Section 3]. The model calculates the $\mathrm{CO}_{2}$ price based on a predefined emission cap for the Netherlands.

\section{REPOWERS model}

The REPOWERS model is an unit-commitment and dispatch simulation model for the Dutch power sector based on Lagrangian Relaxation, developed by ECN [Appendix A] [23]. The model optimizes the hourly commitment and dispatch of generation units based on their variable costs whilst imposing flexibility constraints for a whole year. The model includes power production of intermittent renewable sources, and allows curtailment of wind power. It accounts for exchange with Germany, Belgium, Denmark and the United Kingdom. The model can account for spinning reserves, of which the size can be defined per hour. Input data, including a detailed overview of power plant flexibility, are based on public sources [Section 3]. These are similar to the input data for the MARKAL model.

\section{Soft linking the models}

The MARKAL and REPOWERS models are soft linked according to the soft link methodology for the TIMES and PLEXOS models proposed by Deane et al. [24]. This involves running the models sequentially with the same input parameters, where output from MARKAL serves as input for REPOWERS. The methodology of Deane et al. is adapted slightly: electricity demand is determined exogenously for both models, instead of being calculated by an optimization model, and we focus on the operation of power plants rather than the reliability of the power system. In addition, an extra step is required to define individual units from the more aggregated MARKAL output for REPOWERS ${ }^{1}$.

\section{Post Analysis}

Four performance parameters are calculated in the post analysis. 1) The adequacy of hourly and sub-hourly standing reserves is evaluated by calculating the required reserve sizes, and the supply of these reserves by the available power plants in the scenario.

2) The efficiency reduction of thermal power generators is calculated by comparing their realized efficiencies with their nominal efficiency. Also, the average reduction in efficiency is calculated per scenario weighted to the power generation per power plant.

$3,4)$ The annual Short-Run Profit (SRP) and the discounted payback time (DPT) are calculated to define the profitability of power plants [25]. They are based on the current power system market design, where generators are paid per MWh produced according to the marginal generation cost of each hour. No revenues from providing reserves or capacity are included. The SRP is calculated from the hourly revenues and costs of each individual unit, where the electricity price is determined by the marginal costs of the most expensive generator required to meet power demand:

$S R P=\sum_{t=1}^{8760}\left(\right.$ Price $_{\text {electricity }}(t) *$ Production $_{\text {electricity }}(t)-$ Cost $\left._{\text {fuel }}(t)-\operatorname{Cost}_{V O M}(t)-\operatorname{Cost}_{\text {CO2 }}(t)\right)$

The discounted payback time of each unit also includes the fixed O\&M costs and annualized TCR investment costs, but no interest costs during operation. A discount rate of $7 \%$ is used. The DPT is based on the SRPs calculated for the years 2030 and 2050. We assume that plants are retired after their technical lifetime has been reached.

$$
D P T=\ln \left(\frac{1}{1-\frac{\text { Investment } * \text { DiscountRate }}{\text { SRP }- \text { Cost }_{F O M}}}\right) / \ln (1+\text { DiscountRate })
$$

\footnotetext{
${ }^{1}$ Unit are defined based on pre-set sizes of 700MW for PC, 650 for NGCC and 600 for IGCC are used, as they show the best conversion of MARKAL output to units for REPOWERS
} 


\section{$2.1 \quad$ Scenarios}

Four scenarios are considered in this study: Baseline, Stalemate, Global Union, and Fuel Shift which are based on scenarios by Van den Broek et al. [20]. The four scenarios were updated in this study based on scenarios of the IEA, ECN, the European Climate Foundation and the PRIMES model to include recent developments [3-5,26]. These scenarios are chosen because they explore a range of different climate action policies [Table 1].

Long term projections of the electricity demand in the Netherlands show annual growth rates that range from 0.3$1.1 \%$ per year. The annual electricity demand growth becomes smaller in the Stalemate, Global Union, and Fuel Shift scenarios as a result of improved end-use efficiency. However, a fuel shift towards electricity in transport and heating counters this decrease, for example in the Decarbonized ECF scenario [3]. Based on the shared trends shown by ECN, ECF and PRIMES we assume an annual increases in electricity demand of $1.0 \%$ per year for the Baseline scenario, of $0.8 \%$ per year for the Stalemate and Global Union scenarios, and of $0.45 \%$ for the Fuel Shift scenario $[3,4,26]$.

Table 1: Description of scenarios considered in this study.

\section{Baseline}

This scenario is based on estimates of current trends, and only includes policies that were adopted by 2012. As such, it resembles the Current Policies scenario used by the IEA [5], the Reference case of the European Commission [4] and the Business as Usual scenario of ECN [26]. According to this baseline, no additional governmental action is taken to $\mathrm{Curb}^{\mathrm{CO}} \mathrm{O}_{2}$ emissions. Moreover, energy demand increases rapidly, which is largely supplied from fossil fuels.

Annual increase in electricity demand: $1.0 \% / y r \quad 2050$ Dutch power sector emissions: no cap

\section{Stalemate}

The Stalemate scenario assumes that the developed and developing countries that emit most $\mathrm{CO}_{2}$ fail to reach post-2012 climate agreements. This leads to a "stalemate": no follow-up agreements are made to curb $\mathrm{CO}_{2}$ emissions, and the 2 degree target is not met. The EU maintains its emission trading system, hoping that it may encourage future global climate action, and because it will allow for quick implementation of stringent reduction targets if climate action is taken. Towards the middle of the century, the effects of climate change prompt the EU to reduce its carbon emissions to $40 \%$ of 1990 levels.

Annual increase in electricity demand: $0.8 \% / y r \quad 2050$ Dutch power sector emissions: 16 Mton cap

(60\% reduction compared to 1990$)$

\section{Global Union}

The Global Union scenario assumes 'ideal' development of climate policies, with international climate negotiations reaching an agreement that not just includes the OECD countries, but also large, fast-growing developing countries such as China, India and Brazil. The new climate agreement aims to limit global warming to less than 2 degrees Celsius, which leads to a large switch from fossil to renewable energy sources.

Annual increase in electricity demand: $0.8 \% / \mathrm{yr} \quad 2050$ Dutch power sector emissions: 2 Mton cap

(95\% reduction compared to 1990)

Fuel Shift

The Fuel Shift scenario assumes similar political developments as in the Global Union scenario. Moreover, the Netherlands decide that the share of coal-fired electricity generation should be reduced for environmental and geopolitical reasons. This leads to a shift from coal to natural gas for electricity production, as biomass is used more cost-effectively in the transportation sector. As a result, the total electricity demand is lower in this scenario, and electricity is co-produced during the production of Fischer-Tropsch fuels.

Almost all $\mathrm{CO}_{2}$ prices are calculated with the MARKAL model for the Netherlands based on European $\mathrm{CO}_{2}$ emission reduction targets. The lower bound of the European targets is taken due to the limited availability of renewable resources in the Netherlands, and the presence of energy intensive industry, which both make it relatively harder to realize emissions savings [1]. Predetermined $\mathrm{CO}_{2}$ prices are only used in the Fuel Shift scenario to simulate the effect of high $\mathrm{CO}_{2}$ prices. Overall, a range of $\mathrm{CO}_{2}$ price levels is considered (0-195 $€ / \mathrm{tCO}_{2}$ across the scenarios) [Table 7], which reflects the large uncertainty in $\mathrm{CO}_{2}$-price projections [27]. 
Table 2: Fuel prices used in this study.

\begin{tabular}{|c|c|c|c|c|c|c|}
\hline & & 2030 & & & $2050^{a}$ & \\
\hline & $\begin{array}{c}\text { Coal } \\
\left(€_{2011} / G J\right)\end{array}$ & $\begin{array}{c}\text { Natural Gas } \\
\left(€_{2011} / \mathrm{GJ}\right)\end{array}$ & $\begin{array}{c}\text { Biomass } \\
\left(€_{2011} / \mathrm{GJ}\right)\end{array}$ & $\begin{array}{c}\text { Coal } \\
\left(€_{2011} / \mathrm{GJ}\right)\end{array}$ & $\begin{array}{c}\text { Natural Gas } \\
\left(€_{2011} / \mathrm{GJ}\right)\end{array}$ & $\begin{array}{l}\text { Biomass } \\
\left(€_{2011} / G J\right)\end{array}$ \\
\hline Baseline & 3.4 & 8.9 & 8.0 & 3.8 & 9.7 & 9.0 \\
\hline Stalemate & 3.1 & 8.1 & 8.0 & 3.3 & 8.5 & 9.0 \\
\hline $\begin{array}{l}\text { Global Union, } \\
\text { Fuel Shift }\end{array}$ & 2.2 & 6.6 & 8.0 & 1.2 & 5.1 & 9.0 \\
\hline
\end{tabular}

a) Fuel prices were extrapolated for the years $2040-2050$ with a linear, $2^{\text {nd }}$ degree polynomial or power function: whichever shows the best fit with projections from 2015 until 2035.

All costs are expressed in $€_{2011}$ based on historical exchange rates and the European Power Capital Cost Index [28,29]. Fuel prices are adopted from the World Energy Outlook 2012, because these long-term projections align well with the scenarios of this study [Table 2] [5]. Biomass pellet prices are based on conservative projections, as future developments are highly uncertain (3-9 $€ / G J)[30] . \mathrm{CO}_{2}$ transport and storage costs are estimated at $6 € / \mathrm{tCO}_{2}$ and 8 $€ / \mathrm{tCO}_{2}$ respectively for future deployment of CCS in the Netherlands with a large $\mathrm{CO}_{2}$ transportation network and storage offshore in depleted oil and gas fields [31].

\section{Input data}

\subsection{MARKAL input data}

\section{Power plant input parameters}

A dataset of techno-economic parameters has been constructed from recent sources. Firstly, the current typical stateof-the-art specifications were determined for all power plants based on these sources. Next, the expected developments in costs and efficiencies until 2050 were compared between the sources, and the most likely development was applied to the present-day specifications.

Efficiencies are mostly based on the efficiency projections of Van den Broek and the IEA [5,20]. Conservative values are chosen, because capacity factors are expected to decrease. This will likely increase demand for somewhat cheaper, less efficient installations. Investment costs are based on projections of IEA and ECF, because they correspond with current prices and reflect recent developments (such as solar PV investment cost reductions, and offshore wind power being relatively expensive) [3,5]. Projected O\&M costs are based on IEA costs, which are split between variable and fixed costs based on ratios reported by the GCCSI [5,32].

\section{RES potential}

ECN and PBL projected the future deployment of wind and solar PV power in the Netherlands in 2020 and 2030 [26], and their future potential for 2050 [17]. The 2020 and 2030 projections are set as the minimum installed capacities in the model. From 2030 onwards, the future potentials are set as the maximum capacity that the model can deploy. The baseline is based on their conservative "fixed policy"2 (Min 3.6 GW onshore wind, 1.7 GW offshore wind, $1.5 \mathrm{GW}$ solar PV in 2020. Max 4 GW onshore wind, 16 GW offshore wind and $27 \mathrm{GW}$ solar PV in 2050). The other scenarios are based on the "intended policy" (Min $6 \mathrm{GW}$ onshore wind, 1.7 GW offshore wind, 1.6 GW solar PV in 2020. Max 8 GW onshore wind, $34 \mathrm{GW}$ offshore wind and $53 \mathrm{GW}$ solar PV in 2050).

\footnotetext{
${ }^{2}$ These terms translate as "vastgesteld beleid" and "voorgesteld beleid", which are the scenario names used by ECN in Dutch energy projections [26].
} 


\begin{tabular}{|c|c|c|c|c|c|c|c|c|}
\hline 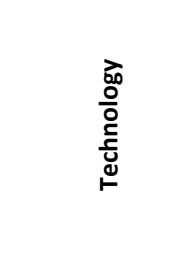 & 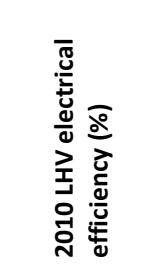 & 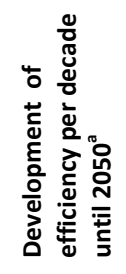 & 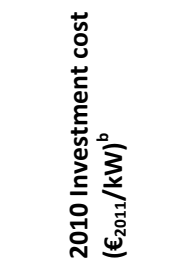 & 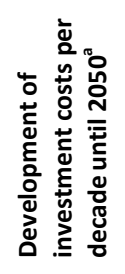 & 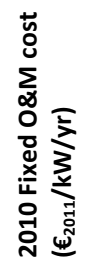 & 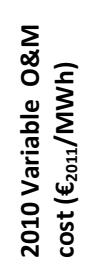 & 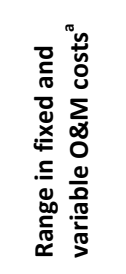 & 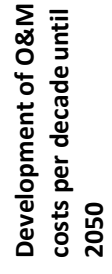 \\
\hline $\mathrm{NGCC}^{\mathrm{c}}$ & $60 \%( \pm 10 \%)$ & $+1.0 \%$-pt & $700( \pm 30 \%)$ & $-2 \%$ & 15 & 1.2 & $( \pm 50 \%)$ & $0 \%$ \\
\hline GT & $38 \%( \pm 5 \%)$ & $+1.0 \%-\mathrm{pt}$ & $370( \pm 10 \%)$ & $0 \%$ & 9 & 0.8 & $( \pm 10 \%)$ & $0 \%$ \\
\hline $\mathbf{P C}^{c, d}$ & $47 \%( \pm 15 \%)$ & $+1.7 \%$-pt & $1500( \pm 40 \%)$ & $-4 \%$ & 25 & 3.0 & $( \pm 60 \%)$ & $0 \%$ \\
\hline IGCC $^{c, e}$ & $47 \%( \pm 15 \%)$ & $+2.0 \%-\mathrm{pt}$ & $1800( \pm 20 \%)$ & $-4 \%$ & 40 & 3.0 & $( \pm 30 \%)$ & $-3 \%$ \\
\hline NGCC-CCS & $52 \%( \pm 10 \%)$ & $+1.3 \%-\mathrm{pt}$ & $1300( \pm 20 \%)$ & $-7 \%$ & 22 & 2.1 & $( \pm 100 \%)$ & $-6 \%$ \\
\hline PC-CCS & $36 \%( \pm 20 \%)$ & $+3.0 \%-\mathrm{pt}$ & $2500( \pm 40 \%)$ & $-9 \%$ & 36 & 5.6 & $( \pm 100 \%)$ & $-7 \%$ \\
\hline IGCC-CCS ${ }^{e}$ & $38 \%( \pm 20 \%)$ & $+2.7 \%-\mathrm{pt}$ & $2600( \pm 30 \%)$ & $-7 \%$ & 57 & 4.5 & $( \pm 30 \%)$ & $-6 \%$ \\
\hline Wind onshore & & & $1230( \pm 30 \%)$ & $-2 \%$ & 18 & & $( \pm 70 \%)$ & $-2 \%$ \\
\hline Wind offshore & & & $3300( \pm 40 \%)$ & $-20 \%$ & 74 & & $( \pm 60 \%)$ & $-16 \%$ \\
\hline Nuclear & & & $3000( \pm 40 \%)$ & $0 \%$ & 73 & & $( \pm 40 \%)$ & $0 \%$ \\
\hline Solar PV & & & $2080( \pm 100 \%)$ & $-25 \%$ & 21 & & $( \pm 100 \%)$ & $-6 \%$ \\
\hline
\end{tabular}

Sources: $[3,5,7,20,32-35]$. The ranges show the range of reported values by these studies. The techno-economic parameters of polygeneration facilities are described in [21]

a) The development shows the projected cumulative improvement of the techno-economic parameters; e.g. NGCC efficiency is projected to be $63 \%(3 \times 1.0 \%)$ in 2040 .

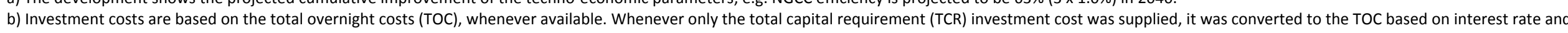
construction time of power plants reported by the specific source [36].

c) The MARKAL model can also apply retrofits to these units if the base plant was built between 2010 and 2020

d) It is assumed that biomass can be co-fired in PC(-CCS) units up to $30 \%$ in 2030 and up to $50 \%$ in 2050 (energy basis), without affecting the techno-economic parameters.

e) The projected IGCC developments apply to a situation in which IGCC plants become a mainstream technology [37]. 


\section{CHP plant input parameters}

\section{Techno-economic parameters}

Based on a literature review, the current typical state-of-the-art and future techno-economic parameters of CHP generators were determined [Table 4]. Future developments consist of a gradual increase in electrical efficiency whilst keeping fixed heat efficiency, and a decrease in investment and O\&M costs. In addition, each unit type was also separately defined as a technology as being equipped with CCS.

Table 4: Techno-economic parameters of current and future CHP plants

\begin{tabular}{|c|c|c|c|c|c|c|c|c|c|c|}
\hline 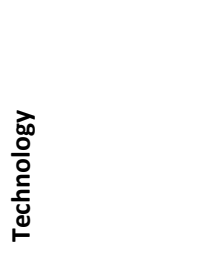 & 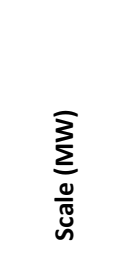 & 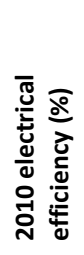 & 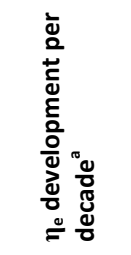 & 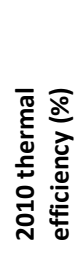 & 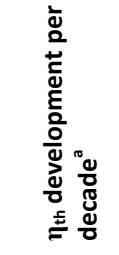 & 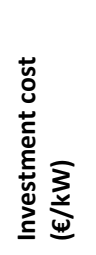 & 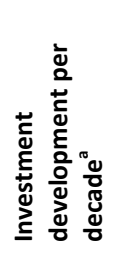 & 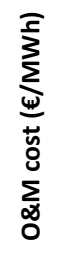 & 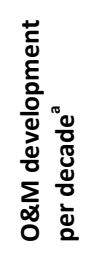 & 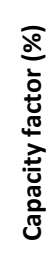 \\
\hline Gas engine $^{b}$ & $2-5$ & 41 & $+1.7 \%-\mathrm{pt}$ & 50 & $-0.5 \%-\mathrm{pt}$ & 589 & $-7 \%$ & 7 & $-3 \%$ & 51 \\
\hline Combined cycle & $125-250$ & 42 & $+1.3 \%-\mathrm{pt}$ & 38 & $0 \%-p t$ & 880 & $-3 \%$ & 6 & $-3 \%$ & 91 \\
\hline Gas turbine $^{b}$ & $25-45$ & 30 & $+1.6 \%-\mathrm{pt}$ & 50 & $0 \%-p t$ & 961 & $-6 \%$ & 5 & $-3 \%$ & 91 \\
\hline Fuel cell ${ }^{c}$ & $0.5-5$ & 42 & $+1.3 \%-\mathrm{pt}$ & 40 & $0 \%-p t$ & 1715 & $-7 \%$ & 14 & $-3 \%$ & 51 \\
\hline
\end{tabular}

Sources: [20,38-44].

a) The development shows the projected cumulative improvement of the techno-economic parameters; e.g. Gas engine electrical efficiency is projected to be $46.1 \%(3 \times 1.7 \%)$ in 2040 .

b) The MARKAL model also considers this unit equipped with CCS, which incurs a $2 \%$-point electric efficiency penalty, and a $13 \%$-point heat efficiency penalty. This increases the investment costs by $€ 1732, € 559$ and $€ 934 / \mathrm{kW}$ for gas engines, combined cycles and gas turbines respectively [41].

c) The presented parameters are for the year 2020, which is the first year that fuel cell technology is available in the model. The MARKAL model also considers this unit equipped with CCS, which incurs a $2 \%$-point electric efficiency penalty, and a $2 \%$-point heat efficiency penalty, at an increase of $536 € / \mathrm{kW}$ in investment costs [41].

\section{Electricity and heat demand}

Gross electricity demand in 2011 amounted to $122 \mathrm{TWh} / \mathrm{yr}$, of which $11 \%$ was produced and consumed locally. This share did not enter the public power grid, because it was used on site, e.g. at industrial sites and hospitals [45]. Future electricity demand is calculated based on a projected annual increase in electricity demand. For the REPOWERS model, the electricity demand pattern is based on the year 2011 demand pattern of grid electricity [46]. Half of the local electricity generation and consumption is assumed to be base-load (constant through time), and the other half has the same pattern as grid demand [47].

Future heat demand is based on projections by ECN per sector, and a must-run/flexible demand ratio per sector that is based on the present-day situation $[48,49]$. Annual heat demand is divided between seasons for flexible demand $[22,50]$, and agricultural demand [51].

For MARKAL, a distinction is made between day (7:00-11:00 \& 15:00-23:00), night (23:00-7:00) and peak (11:00-15:00) heat demand. Must-run units (largely located in the industrial sector) will produce heat throughout the day by definition. The heat demand of flexible units (largely located in the agricultural and services sectors) is based on the seasonal heat demand pattern of a future household, as reported by [22]. The model will build technologies that can generate heat, which may be CHP units or auxiliary boilers. 


\subsection{REPOWERS input data}

In this section, we provide an overview of power plant flexibility parameters, as these are a key input into the model.

The other Repowers input data are included in Appendix C.

\section{Power plant flexibility parameters}

Data on the current and future flexibility of power plants were collected from equipment manufacturers, grey literature and scientific articles, and confirmed with 5 experts [Table 5]. Whenever little or no information is available for the 2020 and 2030 cohorts, we extrapolate the 2000 and 2010 data if sources mention that further specific improvements are achievable. A detailed description of power plant flexibility is provided in Appendix B.

Table 5: Flexibility parameters of power plants per technology, based on Appendix B

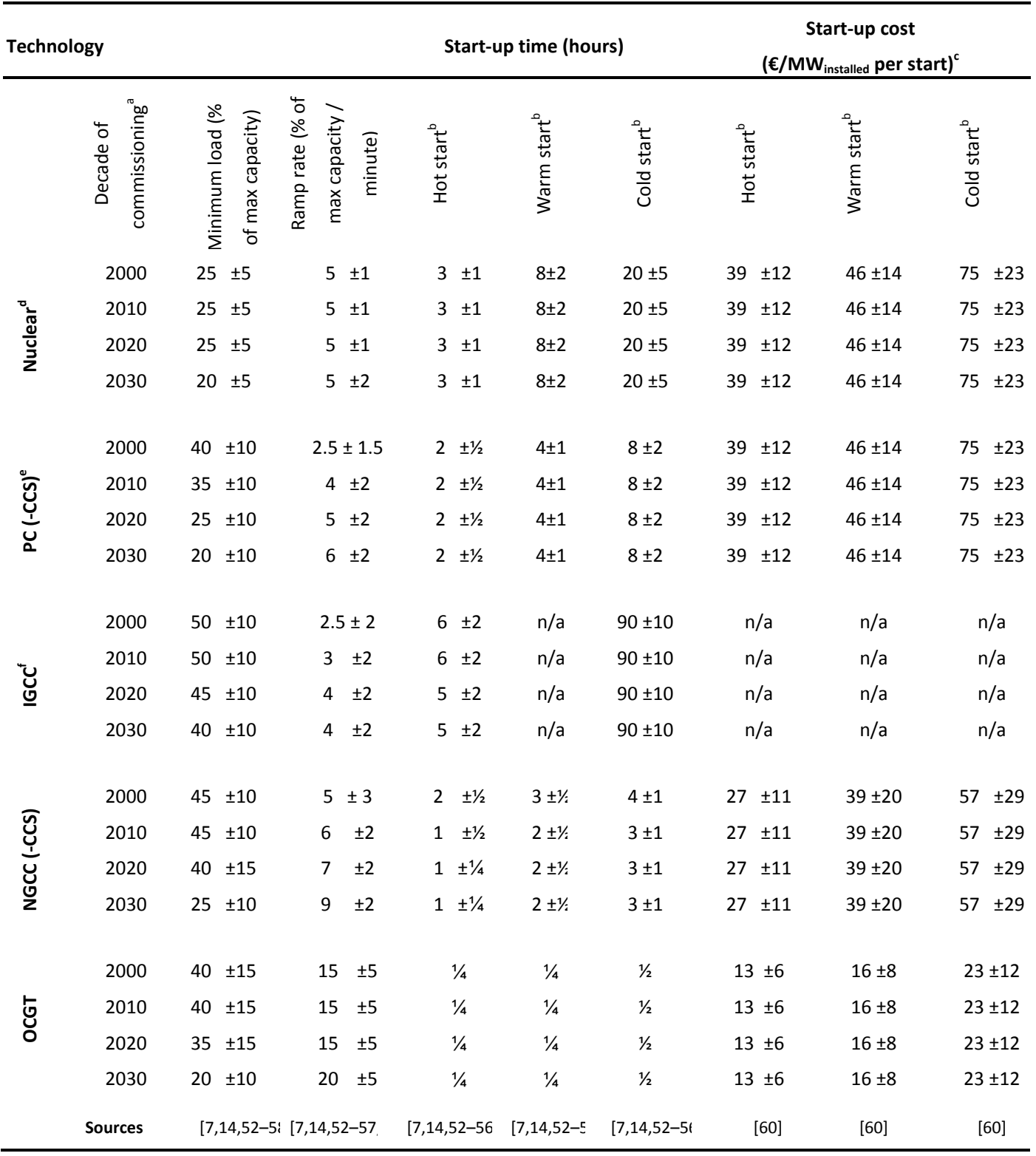

a) Figures depict the typical state-of-the-art performance per decade.

b) Starts are classified based on the elapsed time since shutdown. We distinguish hot (offline for $<12$ hours), warm (offline for $12-72$ hours) and cold (offline for $>72$ hours) starts.

c) The broad definition of start-up costs is used, without accounting for $\mathrm{CO}_{2}$ credit costs [Appendix B]

d) Limited nuclear power plant start-up costs have been found in the literature. Start-up costs equal to those of PC power plants are assumed based on [13].

e) Co-firing of biomass is assumed to not affect the flexibility parameters of PC-CCS power plants.

f) No IGCC warm startup time or start-up costs have been found in the literature. Polygeneration may improve the flexibility of IGCC electricity production, albeit at higher investment costs [61]. 
The results show that modern power plants are relatively flexible, even nuclear and PC(-CCS) power plants. IGCC power plants are relatively inflexible because of their inflexible Air Separation Unit (ASU) and gasifier.

Please note that these figures depict the current and future state-of-the-art flexibility parameters. Older plants are (much) less flexible, as flexibility was less important in the past. Moreover, fast ramp rates and fast startups will result in larger thermal stress on equipment and hence reduce its technical lifetime. Power plant operators may therefore opt for more gradual ramping and startups in practice.

\section{Power plant part-load efficiencies}

State-of-the-art part-load efficiencies were collected from technical reports and manufacturer specifications. Per technology, a second-order part-load efficiency curve is plotted based on the reported data points. These plotted curves express the relative efficiency as a percentage of the full-load efficiency to simplify comparing different technologies [Table 6]. The plotted curves are shown in Figure 2, where it can be seen that the gas turbine based technologies have relatively poor part-load performance, resulting from a lower turbine inlet temperature [39]. Also, the performance penalty of the $\mathrm{CO}_{2}$ capture unit becomes progressively larger at lower load levels, resulting from larger throttling losses to keep sufficient steam pressure to the stripper, and less efficient compression of $\mathrm{CO}_{2}[54,62]$.

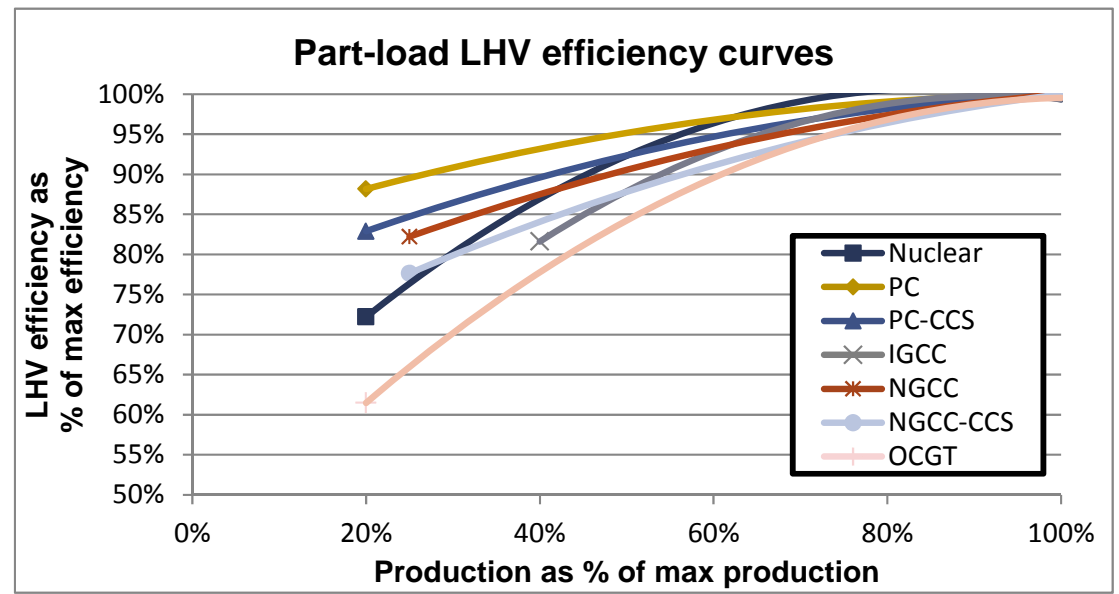

Figure 2: Plotted curves that show the relative part-load efficiency as \% of full-load efficiency.

Table 6: Description of plotted part-load efficiency curves per technology based on curves from literature

\begin{tabular}{cccccccc}
\hline Index ${ }^{\mathrm{a}}$ & Nuclear & PC & PC-CCS & IGCC & NGCC & $\begin{array}{c}\text { NGCC- } \\
\text { CCS }\end{array}$ & OCGT \\
\hline $\boldsymbol{a}$ & 0.522 & 0.818 & 0.746 & 0.432 & 0.715 & 0.648 & 0.406 \\
$\boldsymbol{b}$ & 1.135 & 0.353 & 0.458 & 1.225 & 0.478 & 0.570 & 1.155 \\
$\boldsymbol{c}$ & -0.66 & -0.17 & -0.20 & -0.66 & -0.19 & -0.22 & -0.57 \\
$\boldsymbol{r}^{2}$ & 0.988 & 0.841 & $\mathrm{~b}$ & 0.985 & 0.877 & $\mathrm{c}$ & 0.966 \\
\multirow{2}{*}{ Sources } & {$[53]$} & {$[53,55,56,63,64]$} & {$[54,62,65]$} & {$[53]$} & {$[39,55,56,61,66-$} & {$[54,68]$} & {$[55,69-$} \\
& & & & & $68]$ & & $71]$ \\
\hline
\end{tabular}

a) Curves are described by the function $y=a+b x+c x^{2}$, where $x$ is the load of the power plant as $\%$ of max load.

b) Curve is based on the PC curve without CCS, which is reduced by an efficiency penalty that ranges from $8 \%$-points at full load to $9 \%$-points at $40 \%$ load. No $r^{2}$ is associated with this approach.

c) Curve is based on the NGCC curve without CCS, which is reduced by an efficiency penalty that ranges from $7 \%$-points at full load to $8 \%$-points at $40 \%$ load. No ${ }^{2}$ is associated with this approach.

\section{Power plant outages}

Power plant outage patterns are calculated as stochastically, exogenously to the model. Large coal and natural gas fired power plants are modeled as unavailable for $5 \%$ of the time on average $[72,73]$. Once unavailable, the mean time to repair is modeled to be 50 hours $[74,75]$. 


\section{Results}

\subsection{Power system results}

The most cost-effective power system configurations are calculated with MARKAL [Figure 3]. For the Stalemate, Global Union and Fuel Shift scenarios with lower emission targets, a clear shift can be seen towards renewables and CCS capacity. In the Global Union scenarios, the PC-CCS capacity is co-fired with biomass up to the technical limits, resulting in negative emissions. In the Fuel Shift scenario, 0.1-0.7 GW $\mathrm{e}$ power generation capacity is available at polygeneration plants.

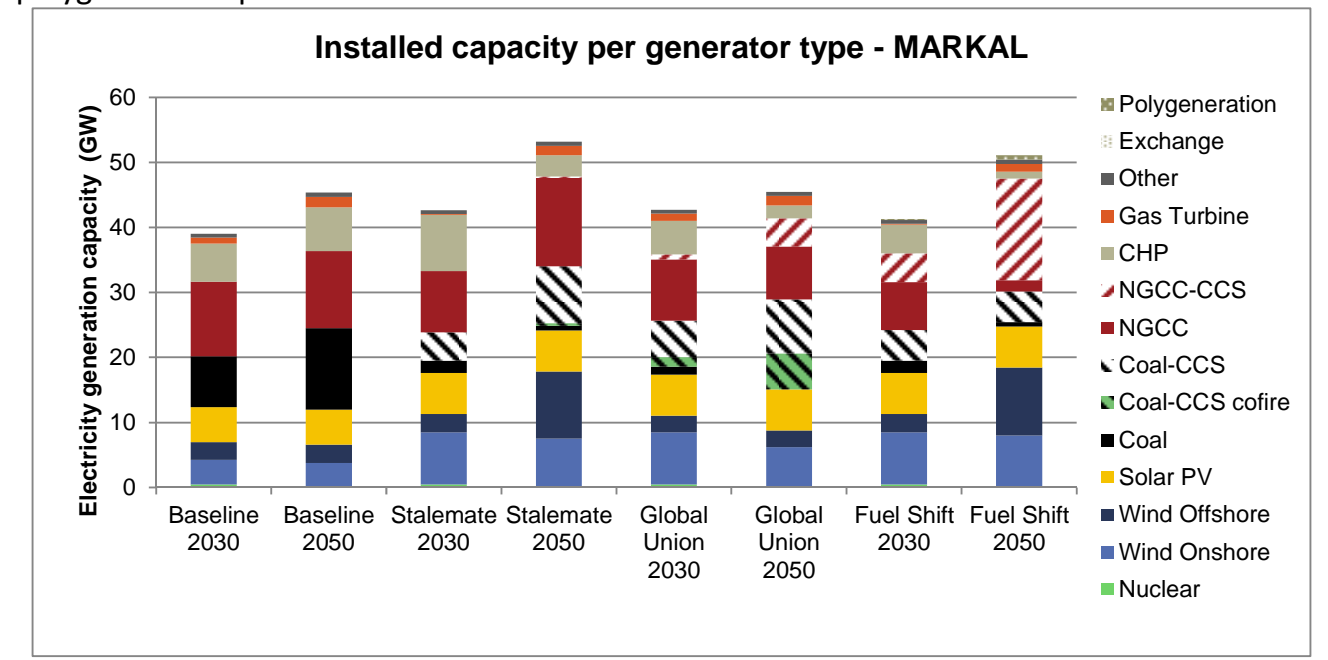

Figure 3: Generation capacities calculated with MARKAL model

Figure 4 shows the annual power generation per generator as calculated with REPOWERS. Low-carbon, capital intensive generators like renewables and coal-fired power plants deliver the largest share of generated electricity in all scenarios. The remainder is delivered by natural gas fired generators, resulting from the relatively high natural gas prices. The REPOWERS results resemble the MARKAL results strongly [Figure 5]. One main difference is observed: NGCC power production is reduced by $50-80 \%$, as it is replaced by imports of cheaper, base-load power from abroad in the REPOWERS model. Also, PC(-CCS) power production decreases by up to $20 \%$ in scenarios with large imports. In scenarios with exports, PC(-CCS) power production increases by up to $20 \%$, which may be the result of its better partload efficiency and minimum load level compared to NGCC(-CCS) generators. Up to $4 \%$ of demand is generated by polygeneration facilities in the Fuel Shift outcome of MARKAL, and replaced by PC-CCS generation in the REPOWERS runs.

MARKAL slightly overestimated the required thermal capacity: $9 \%( \pm 8 \%)$ of the total generation capacity is not utilized, largely because of the large volumes of imported power. In the Stalemate and Fuel Shift 2050 scenarios with net power export, $1 \%$ and $6 \%$ of capacity is not used. 


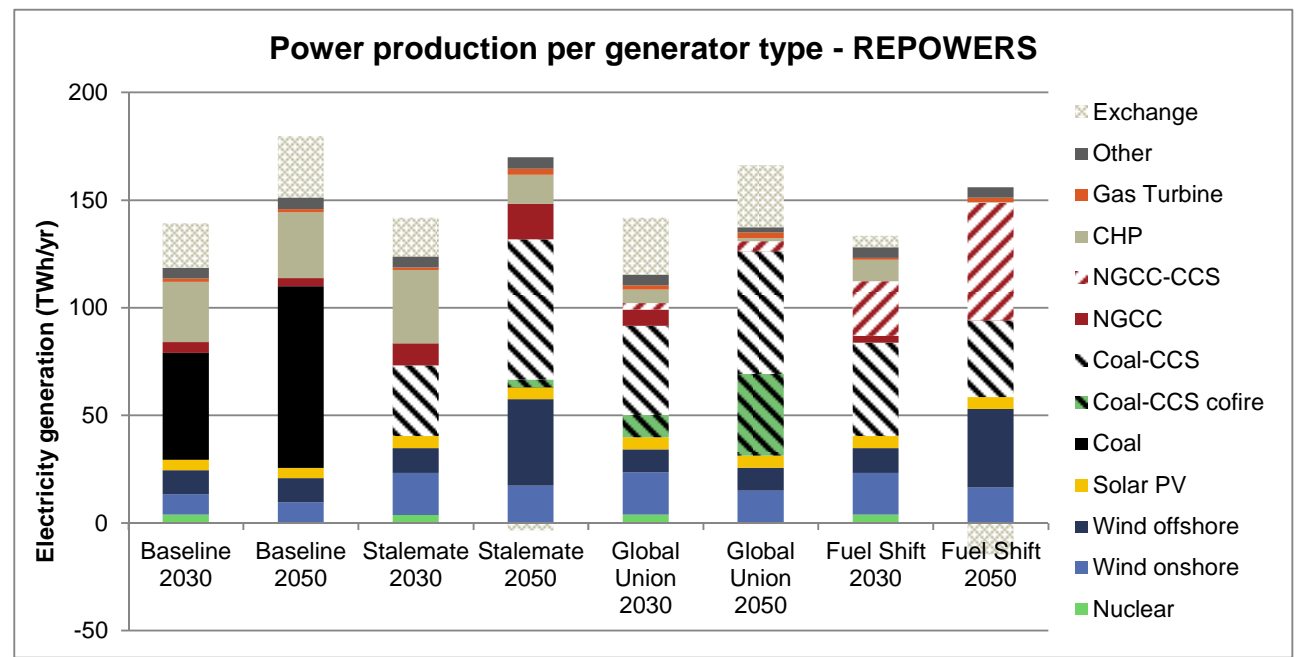

Figure 4: Electricity generation per scenario as calculated with the REPOWERS model

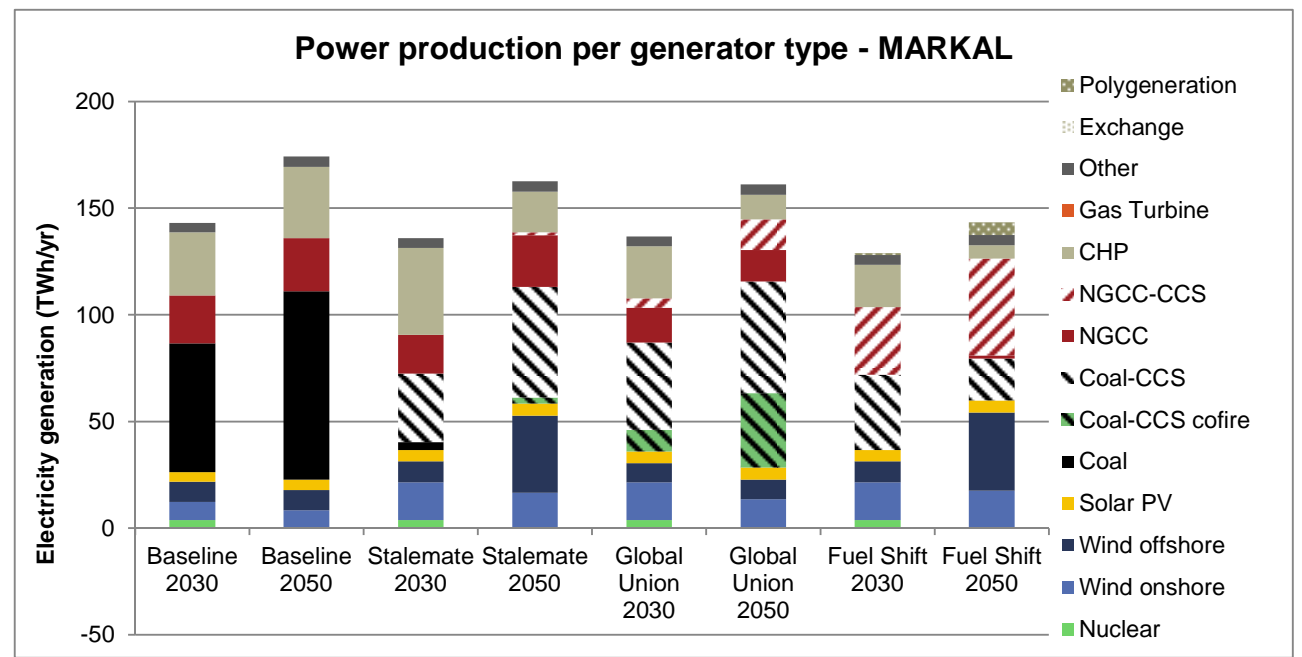

Figure 5 Electricity generation per scenario as calculated with the MARKAL model

Electricity is generally imported from other countries, as shown in Figure 6. The relatively low-cost generation by renewable, nuclear and coal-fired generators abroad is responsible for this. Only in the Stalemate and Fuel Shift 2050 scenarios, the large share of renewables in the Netherlands decreases the net exchange volume. The total trading volume is not much affected. It is higher in the Global Union scenarios (43 TWh/year) than in the other scenarios (36 TWh/year, $\pm 3 \mathrm{TWh}$ ).

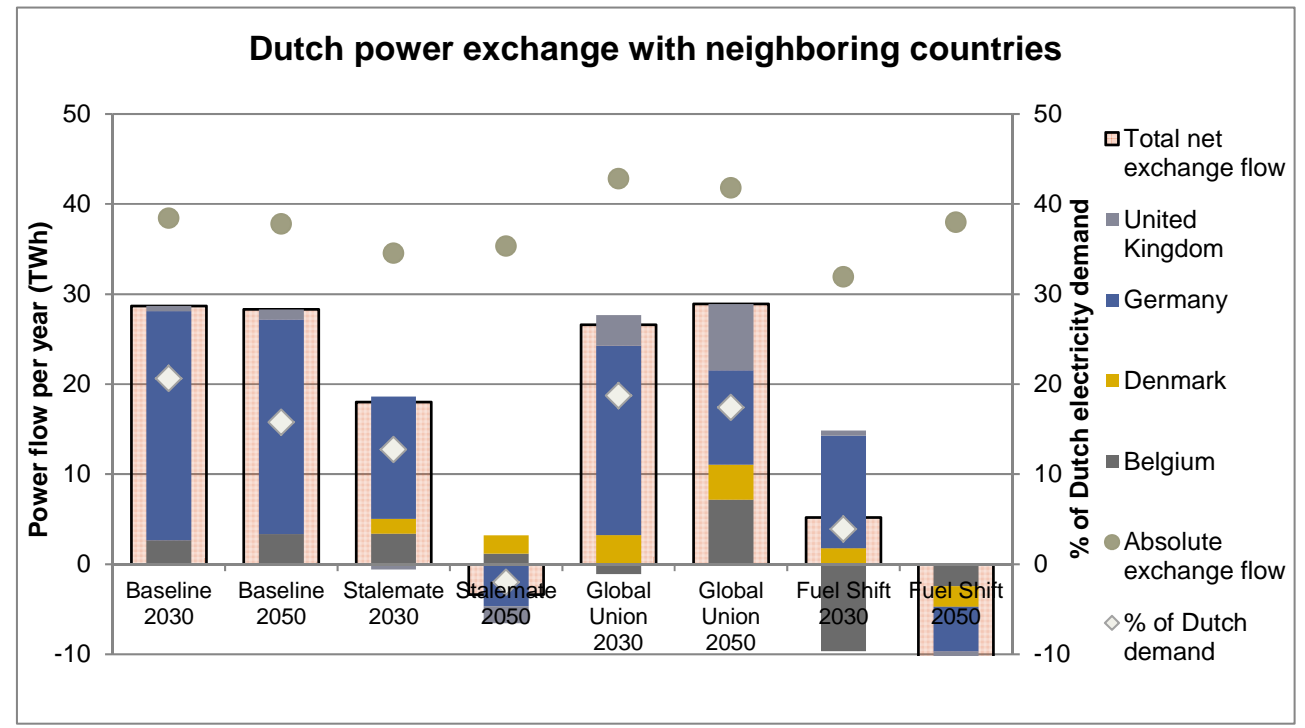

Figure 6: Net power exchange with neighboring countries per scenario as calculated with REPOWERS model 
Table 7: Power system performance data of the Netherlands for all scenarios

\begin{tabular}{|c|c|c|c|c|c|c|c|c|}
\hline & $\begin{array}{c}\text { Baseline } \\
2030\end{array}$ & $\begin{array}{c}\text { Baseline } \\
2050\end{array}$ & $\begin{array}{l}\text { Stale- } \\
\text { mate } \\
2030 \\
\end{array}$ & $\begin{array}{l}\text { Stale- } \\
\text { mate } \\
2050 \\
\end{array}$ & $\begin{array}{l}\text { Global } \\
\text { Union } \\
2030\end{array}$ & $\begin{array}{l}\text { Global } \\
\text { Union } \\
2050\end{array}$ & $\begin{array}{l}\text { Fuel } \\
\text { Shift } \\
2030\end{array}$ & $\begin{array}{l}\text { Fuel } \\
\text { Shift } \\
2050\end{array}$ \\
\hline $\begin{array}{l}\text { Electricity demand } \\
\text { [TWh/yr] }\end{array}$ & 147 & 180 & 142 & 166 & 142 & 166 & 133 & 141 \\
\hline $\mathrm{CO}_{2}$ price $\left[€ / \mathrm{tCO}_{2}\right]$ & 0 & 0 & 39 & 121 & 66 & 124 & 95 & 195 \\
\hline $\begin{array}{l}\text { Annual emissions } \\
\left.\text { [MtCO }_{2} / \mathrm{yr}\right]^{\mathrm{a}}\end{array}$ & 48 & 70 & 18 & 6 & 10 & -18 & 11 & 9 \\
\hline $\begin{array}{l}\text { Annual wind curtailment } \\
\text { [\% of potential }^{\text {production] }{ }^{a}}\end{array}$ & $0.4 \%$ & $0.4 \%$ & $2.8 \%$ & $7.7 \%$ & $1.6 \%$ & $3.4 \%$ & $3.1 \%$ & $14.1 \%$ \\
\hline Efficiency reduction [\%] $]^{a, b}$ & $1.0 \%$ & $1.0 \%$ & $0.7 \%$ & $1.5 \%$ & $1.4 \%$ & $1.6 \%$ & $0.7 \%$ & $1.4 \%$ \\
\hline $\begin{array}{l}\text { Average variability of } \\
\text { residual load }[\mathrm{MW} / \mathrm{h}]^{\mathrm{a}, \mathrm{c}}\end{array}$ & 648 & 754 & 443 & 817 & 570 & 1041 & 410 & 771 \\
\hline
\end{tabular}

a) Calculated with the REPOWERS model.

b) The efficiency reduction is the percentage -difference between the average realized efficiency of a thermal power generator and its nominal, full load, efficiency. The weighted average of all generators is calculated based on the annual power production of each individual generator. The reduction is caused by lower part-load efficiencies [Figure 2].

c) The residual load is defined as the load minus IRES production and exports. This residual load has to be provided by thermal power plants.

$\mathrm{CO}_{2}$ emissions increase strongly in the Baseline 2050 scenario, because the share of coal-fired generation increases by 70\%. Despite its early merit order position, significant shares of wind power production are curtailed, especially in the Stalemate and Fuel Shift scenarios [Table 7]. This curtailment primarily occurs during high wind, low load situations, when sufficient thermal capacity is needed to supply reserves. High renewable penetration levels in neighboring countries are simulated in the Global Union scenarios, which also affect wind curtailment in the Netherlands.

The reduction in efficiency of the 2030 low-carbon scenarios is comparable to the 2030 and 2050 Baseline efficiency reduction ( 1\%), while the 2050 low-carbon scenarios have a slightly higher reduction ( 1.5\%). The efficiency reduction correlates strongly to the average hourly variability in power output of thermal power plants $\left(r^{2}=0.81\right)$. This variability in low-carbon scenarios varies $\pm 40 \%$ from that of the Baseline scenarios. Four underlying factors correlate with the efficiency reduction: (1) the absolute interconnection flows $\left(r^{2}=0.67\right)$ : power exchange causes variability; (2) centralized thermal power production $\left(r^{2}=0.62\right)$ : the efficiency of large power plants is primarily affected [Figure 7]; (3) IRES power production ( $\left.r^{2}=0.46\right)$ : IRES increase the variability in the system; (4) the variability of the load itself $\left(r^{2}=0.38\right)$. Especially NGCC(-CCS) and GT units operate flexibly, so they contribute most strongly to the efficiency reduction [Figure 7].

The efficiency reductions increase the specific $\mathrm{CO}_{2}$ emissions by $0.004-0.006 \mathrm{tCO}_{2} / \mathrm{MWh}$ in the Baseline scenarios, and 0.0004-0.0007 $\mathrm{tCO}_{2} / \mathrm{MWh}$ in the low-carbon scenarios. Even if these extra emissions would be fully attributed to IRES, the IRES emissions would be very low. 


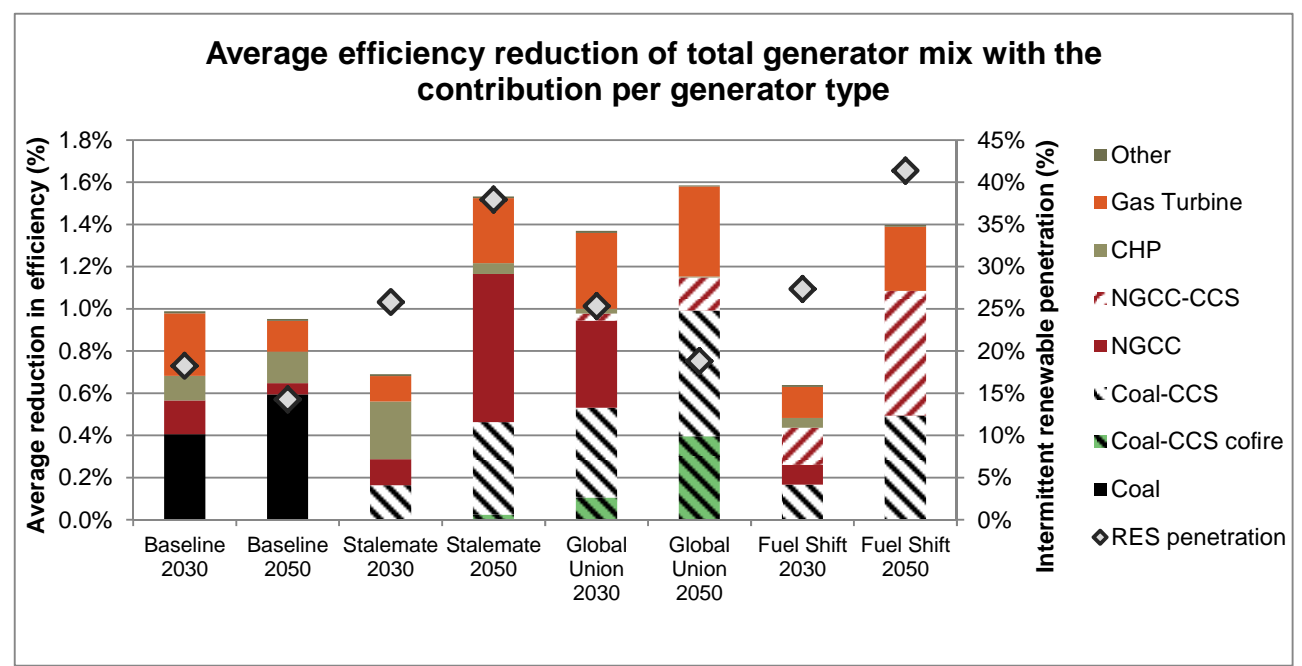

Figure 7: Average energy efficiency reduction of all thermal generators per scenario compared to full-load efficiency, split between the contributions per generator type.

The power system costs vary between scenarios [Figure 8 and Table 8]. The fuel, $\mathrm{CO}_{2}$ and investment costs are the most important components, while the variable O\&M costs are $10 \%$ of the fuel costs, and fixed O\&M costs $20-25 \%$ of the annualized investment costs. Startup costs are negligible. The total costs are affected by five factors:

1) Larger share of renewables: lower fuel cost and higher investment cost, as shown in the Stalemate 2050 and Fuel Shift 2050 scenarios.

2) Biomass co-firing: higher fuel and lower $\mathrm{CO}_{2}$ costs. The Global Union 2050 scenario realizes $18 \mathrm{MtCO}_{2}$ negative emissions with co-firing of biomass in PC-CCS plants, which are worth 2.2 billion Euros.

3) Higher $\mathrm{CO}_{2}$ price: higher $\mathrm{CO}_{2}$ costs. These costs comprise up to $14 \%$ of total system costs in the Fuel Shift 2050 scenario.

4) More electricity imports: lower short-run costs. Imports mainly reduce CHP and NGCC(-CCS) electricity generation in the Netherlands as compared to the MARKAL simulations.

5) More generation capacity: higher investment costs. Sufficient capacity is available in the scenarios to meet peak demand and reserves. Comparing Figure 4 and Figure 8 shows that NGCC and GT mid-merit and peak load capacity is relatively expensive compared to the power it generates: 2-5 times, and 1.5-3 times the average total costs per MWh, respectively.

Comparing the power system costs to the electricity price shows that the price does not cover the costs of the system in most scenarios: only $84 \%( \pm 30 \%)$ is covered [Table 8 ]. This suggests that the current energy-based power sector market design does not seem suitable for future low-carbon scenarios. Moreover, Table 11 shows that power generation in low-carbon power systems is on average $17 \%( \pm 15 \%)$ more expensive per MWh than in the baseline. On average, $25 \%$ of this increase in cost is caused by the $\mathrm{CO}_{2}$ price. The opposite is true for the Global Union scenarios, which have lower electricity prices than the baseline thanks to negative emissions and cheap imports. 


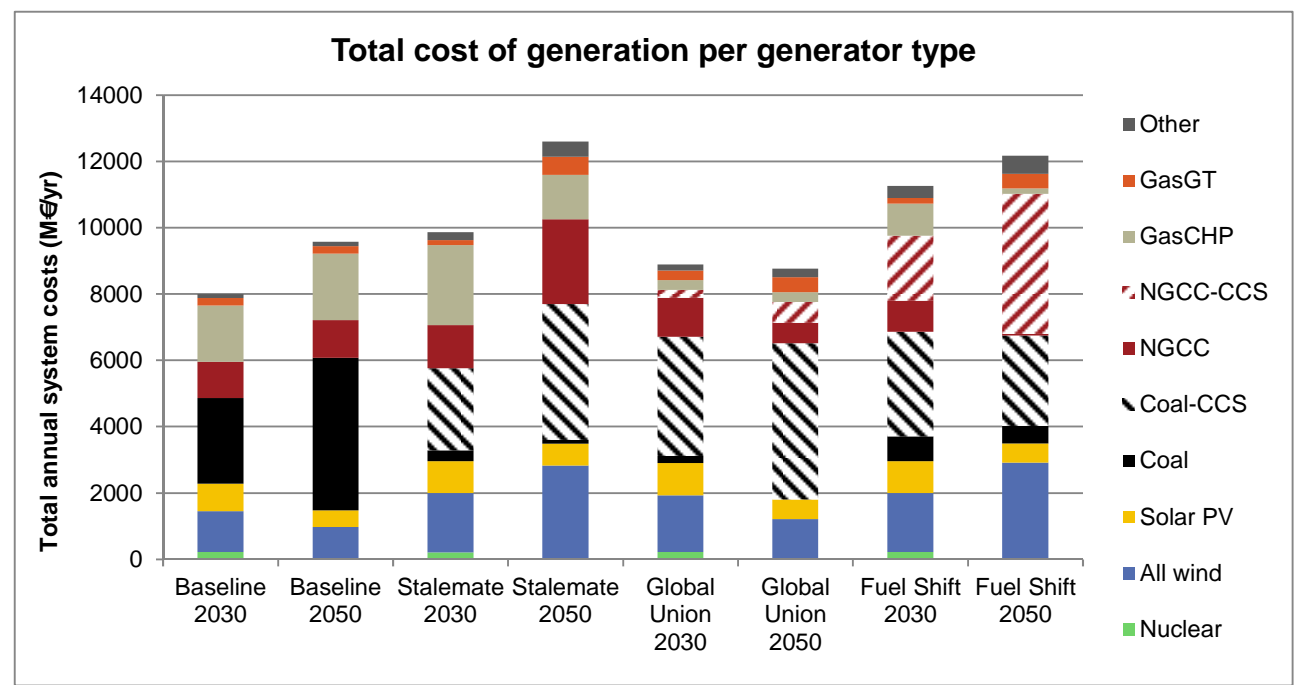

Figure 8: Total cost of generation split between the different types of generators.

Table 8: Power system cost data of the Netherlands for all scenarios

\begin{tabular}{|c|c|c|c|c|c|c|c|c|}
\hline & $\begin{array}{c}\text { Baseline } \\
2030\end{array}$ & $\begin{array}{l}\text { Baseline } \\
2050\end{array}$ & $\begin{array}{c}\text { Stale- } \\
\text { mate } \\
2030 \\
\end{array}$ & $\begin{array}{c}\text { Stale- } \\
\text { mate } \\
2050 \\
\end{array}$ & $\begin{array}{c}\text { Global } \\
\text { Union } \\
2030 \\
\end{array}$ & $\begin{array}{c}\text { Global } \\
\text { Union } \\
2050 \\
\end{array}$ & $\begin{array}{l}\text { Fuel } \\
\text { Shift } \\
2030 \\
\end{array}$ & $\begin{array}{l}\text { Fuel } \\
\text { Shift } \\
2050 \\
\end{array}$ \\
\hline Fuel costs [M€/yr] & 2876 & 4019 & 3138 & 4273 & 2520 & 4732 & 3294 & 2986 \\
\hline Coal [M€/yr] & 1283 & 2335 & 1264 & 2318 & 1109 & 1465 & 1381 & 744 \\
\hline Natural Gas [M€/yr] & 1528 & 1666 & 1812 & 1673 & 810 & 373 & 1864 & 2239 \\
\hline Biomass [M€/yr] & 0 & 0 & 0 & 264 & 551 & 2892 & 0 & 0 \\
\hline Other [M€/yr] & 65 & 19 & 63 & 18 & 50 & 2 & 50 & 3 \\
\hline Variable $O \& M$ costs [M€/yr] & 217 & 331 & 234 & 394 & 283 & 489 & 282 & 249 \\
\hline Start-up costs [M€/yr] & 36 & 40 & 44 & 59 & 52 & 61 & 40 & 54 \\
\hline $\mathrm{CO}_{2}$ costs $[\mathrm{M} € / \mathrm{yr}]$ & 0 & 0 & 697 & 931 & 673 & -2536 & 1068 & 1693 \\
\hline $\begin{array}{l}\text { Total short-run system costs } \\
\text { (M€/yr) }\end{array}$ & 3129 & 4390 & 4113 & 5657 & 3528 & 2746 & 4684 & 4982 \\
\hline Investment costs [M€/yr] & 3941 & 4185 & 4669 & 5528 & 4523 & 5008 & 5444 & 5899 \\
\hline Fixed $O \& M$ costs $[M € / y r]$ & 962 & 1042 & 1116 & 1358 & 882 & 1067 & 1165 & 1339 \\
\hline Total system costs $[\mathrm{M} € / \mathrm{yr}]^{\mathrm{a}}$ & 8033 & 9618 & 9899 & 12543 & 8933 & 8821 & 11292 & 12220 \\
\hline $\begin{array}{l}\text { Average electricity price } \\
(€ / \mathrm{MWh})^{b}\end{array}$ & 61 & 68 & 72 & 85 & 56 & 31 & 71 & 51 \\
\hline $\begin{array}{l}\text { Average total generation } \\
\text { costs }(€ / \mathrm{MWh})^{\mathrm{c}}\end{array}$ & 68 & 64 & 80 & 74 & 77 & 64 & 88 & 78 \\
\hline
\end{tabular}

a) Total annual system costs also include annualized share of the investment cost (based on a discount rate of $7 \%$ ) and the fixed O\&M costs.

b) Average electricity price calculated with the REPOWERS model according to the current market design (payment per MWh generated, on par with the production cost of the marginal generator of each hour).

c) Average total generation costs calculated by dividing the "total system costs" by the amount of electricity generated in the Netherlands.

\subsection{Flexibility of the system}

System flexibility is assessed by determining if sufficient reserves are available, and by zooming in on the flexibility of individual generators and the generation pattern of a typical week. As shown in Figure 9, the scenarios differ from each other in the reserve sizes that are available at least $99 \%$ of the time (depicted by the bars), and the availability of sufficient reserves (depicted by the diamonds). Especially the spinning reserves are difficult to fulfill at all times, as sufficient thermal units need to be online to supply these reserves. This is especially a concern in the Fuel Shift 2050 scenario, where relatively few units have to supply large amounts of spinning reserves during periods of high wind power production. Sub-hourly standing reserves are largely supplied by gas turbines and CHP units, while NGCC(-CCS) units supply an important part of the hourly standing reserves. In the Fuel Shift 2050 scenario, a lack of (mainly natural-gas fired) capacity reduces the available hourly standing reserves. Sufficient down reserves can be supplied at all times, either by thermal power generators or curtailed renewable generators. 
To zoom in on the flexibility and profitability of power plants, a selection of three typical new power plants was made per scenario: PC (-CCS), NGCC (-CCS) and GT power plants, which traditionally represent base-load, mid-load and peakload generation, respectively. These new power plants have better efficiencies and flexibility specifications than older plants, and are most frequently committed within their class.

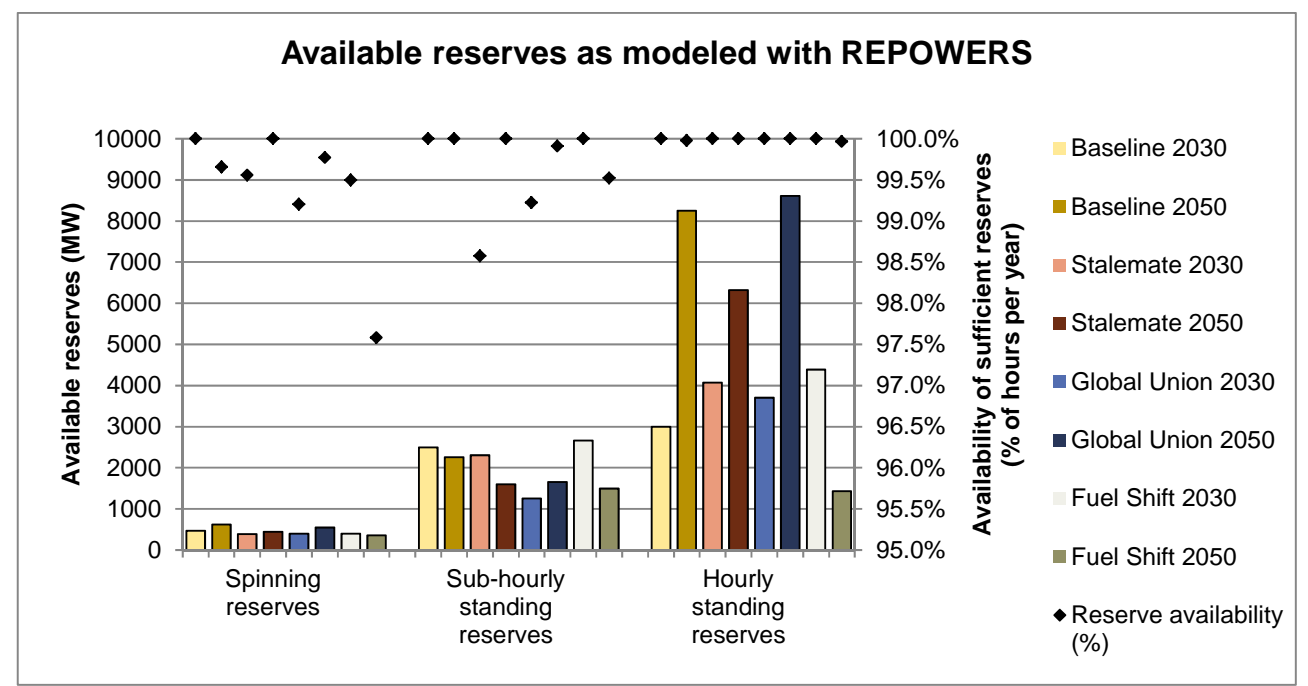

Figure 9: Modeled reserve sizes with $>99 \%$ availability, and the availability of sufficient reserve for 8760 hours per year.

The flexibility performance of the generators does not differ much between the scenarios, as shown in Table 9. The PC-power plants (which are equipped with CCS and co-fired with biomass in some scenarios) show high capacity factors and little variability in output. As a result, the reduction in efficiency is also very limited (0.1-0.3 \%-point). In contrast, NGCC plants (equipped with CCS in the Global Union and Fuel Shift scenarios) have very low capacity factors in all scenarios but the Fuel Shift scenario: they have in fact become balancing plants, with high variability in output and many start-ups. Their efficiency is reduced by 0.3-1.7\%-point compared to their nominal efficiency. The role of gas turbine generators has shifted from peak-load generator to supplier of spinning and sub-hourly reserve capacity. These generators often run near the minimum level, which causes a substantial reduction in efficiency of 4.6-8.5 \%points.

At a unit level, all low-carbon scenarios show higher start-up costs and higher variability of PC(-CCS) and NGCC(-CCS) units than the Baseline scenario, which is expected because of the larger share of renewable generators. The exception is the relatively low variability of the Fuel Shift scenarios, where base-load generators with CCS are an attractive generator type, also for exporting power. The efficiency reduction is not considerably affected: the adverse effects of large shares of renewables on individual units appear limited.

The 2050 generation patterns of week 21, a springtime week with high renewable production, are shown in Figure 10, together with the reserve requirements and load. All scenarios but the Fuel Shift scenario rely heavily on PC(-CCS) power plants. These turn out to be flexible enough to adapt to fast variations: In the Global Union scenario, the system is able to run reliably with these generators and $1.5 \mathrm{GW}$ of gas turbine capacity (5\% of total thermal power plant capacity). Both generator types tend to avoid startup costs and to ramp back rather than be switched off, so that they can supply spinning reserves. In all scenarios but the Baseline scenario, the solid-fuel fired power plants are equipped with CCS to lower their emissions. Natural gas fired capacity has a late position in the merit order, and is utilized for both reserve provision and limited power production. NGCC(-CCS) generators are frequently switched off in all low-carbon scenarios when residual demand is small. Only the Fuel Shift scenario has a large share of NGCC-CCS generation, which is still ramped back during hours of little residual load. Wind power production makes up a large share of power production, and together with Solar PV largely determines the required size of reserves. Exchange with neighboring countries plays an important role, as the trade volumes are sizable. Renewable electricity production and power exchange dampen the day-night variations in residual load in this week, but they can also exacerbate variations depending on (foreign) renewable electricity generation. 


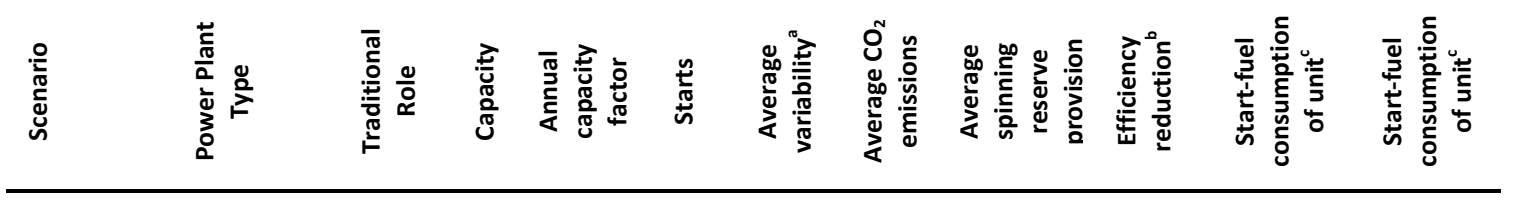

\begin{tabular}{|c|c|c|c|c|c|c|c|c|c|c|c|}
\hline & & & $\sum$ & ฮ & $\underset{⿱ 亠}{\#}$ & 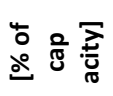 & Ơ & 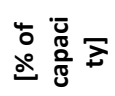 & ذे & 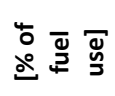 & $\stackrel{\Xi}{\Sigma}$ \\
\hline \multirow{3}{*}{ 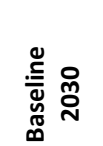 } & PC 2030 & Base & 700 & $91 \%$ & 17 & $1 \%$ & 0.67 & $4.8 \%$ & $0.1 \%$ & $0.3 \%$ & 131 \\
\hline & NGCC 2030 & Mid & 600 & $11 \%$ & 53 & $4 \%$ & 0.34 & $0.7 \%$ & $1.0 \%$ & $3.7 \%$ & 127 \\
\hline & GT & Peak & 100 & $22 \%$ & 9 & $8 \%$ & 0.64 & $9.5 \%$ & $7.8 \%$ & $0.1 \%$ & 1 \\
\hline \multirow{3}{*}{ 竞 울 } & PC 2040 & Base & 700 & $89 \%$ & 4 & $1 \%$ & 0.66 & $7.2 \%$ & $0.2 \%$ & $0.1 \%$ & 31 \\
\hline & NGCC 2040 & Mid & 600 & $15 \%$ & 54 & $5 \%$ & 0.33 & $1.4 \%$ & $1.1 \%$ & $2.7 \%$ & 130 \\
\hline & GT & Peak & 100 & $11 \%$ & 77 & $8 \%$ & 0.60 & $3.7 \%$ & $5.7 \%$ & $0.8 \%$ & 8 \\
\hline \multirow{3}{*}{ 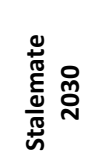 } & PC-CCS 2030 & Base & 700 & $91 \%$ & 11 & $0 \%$ & 0.08 & $4.8 \%$ & $0.2 \%$ & $0.2 \%$ & 85 \\
\hline & NGCC 2010 & Mid & 600 & $38 \%$ & 187 & $9 \%$ & 0.34 & $2.5 \%$ & $0.3 \%$ & $3.6 \%$ & 449 \\
\hline & GT & Peak & 100 & $29 \%$ & 4 & $12 \%$ & 0.58 & $9.9 \%$ & $4.6 \%$ & $0.0 \%$ & 0 \\
\hline \multirow{3}{*}{ 龒 } & PC-CCS 2040 & Base & 700 & $89 \%$ & 9 & $0 \%$ & -0.08 & $4.9 \%$ & $0.3 \%$ & $0.2 \%$ & 69 \\
\hline & NGCC 2040 & Mid & 600 & $41 \%$ & 158 & $11 \%$ & 0.33 & $4.2 \%$ & $1.7 \%$ & $2.9 \%$ & 379 \\
\hline & GT & Peak & 100 & $22 \%$ & 8 & $4 \%$ & 0.62 & $9.5 \%$ & $6.9 \%$ & $0.0 \%$ & 1 \\
\hline \multirow{3}{*}{ 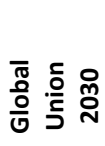 } & PC-CCS 2030 & Base & 700 & $92 \%$ & 6 & $1 \%$ & 0.04 & $5.0 \%$ & $0.1 \%$ & $0.1 \%$ & 46 \\
\hline & NGCC-CCS 2030 & Mid & 600 & $59 \%$ & 108 & $8 \%$ & 0.04 & $3.3 \%$ & $0.7 \%$ & $1.2 \%$ & 259 \\
\hline & GT & Peak & 100 & $21 \%$ & 7 & $3 \%$ & 0.63 & $9.54 \%$ & $7.5 \%$ & $0.0 \%$ & 1 \\
\hline \multirow{3}{*}{ 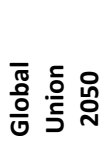 } & PC-CCS 2040 & Base & 700 & $89 \%$ & 53 & $2 \%$ & -0.24 & $4.9 \%$ & $0.3 \%$ & $1.0 \%$ & 408 \\
\hline & NGCC-CCS 2040 & Mid & 600 & $21 \%$ & 146 & $6 \%$ & 0.04 & $1.6 \%$ & $1.3 \%$ & $4.6 \%$ & 350 \\
\hline & GT & Peak & 100 & $20 \%$ & 11 & $1 \%$ & 0.65 & $9.6 \%$ & $8.4 \%$ & $0.1 \%$ & 1 \\
\hline \multirow{3}{*}{ 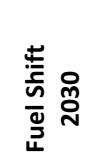 } & PC-CCS 2030 & Base & 700 & $90 \%$ & 6 & $0 \%$ & 0.08 & $4.8 \%$ & $0.2 \%$ & $0.1 \%$ & 46 \\
\hline & NGCC-CCS 2030 & Mid & 600 & $73 \%$ & 143 & $4 \%$ & 0.04 & $3.6 \%$ & $0.4 \%$ & $1.3 \%$ & 343 \\
\hline & GT & Peak & 100 & $21 \%$ & 13 & $4 \%$ & 0.66 & $8.9 \%$ & $8.6 \%$ & $0.1 \%$ & 1 \\
\hline \multirow{3}{*}{ 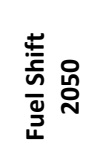 } & PC-CCS 2040 & Base & 700 & $87 \%$ & 13 & $1 \%$ & 0.08 & $5.0 \%$ & $0.2 \%$ & $0.2 \%$ & 100 \\
\hline & NGCC-CCS 2040 & Mid & 600 & $74 \%$ & 112 & $3 \%$ & 0.04 & $3.7 \%$ & $0.4 \%$ & $1.1 \%$ & 269 \\
\hline & GT & Peak & 100 & $20 \%$ & 6 & $1 \%$ & 0.65 & $9.6 \%$ & $8.6 \%$ & $0.0 \%$ & 1 \\
\hline
\end{tabular}

a) The average variability is calculated for all 8760 hours per year.

b) The reduction in efficiency compared to the nominal efficiency, as caused by lower part-load efficiencies. The realized efficiency is calculated from the annual fuel consumption and annual power production.

c) The fuel consumption is based on consumption approximations by the authors, as shown in Table 6 . 


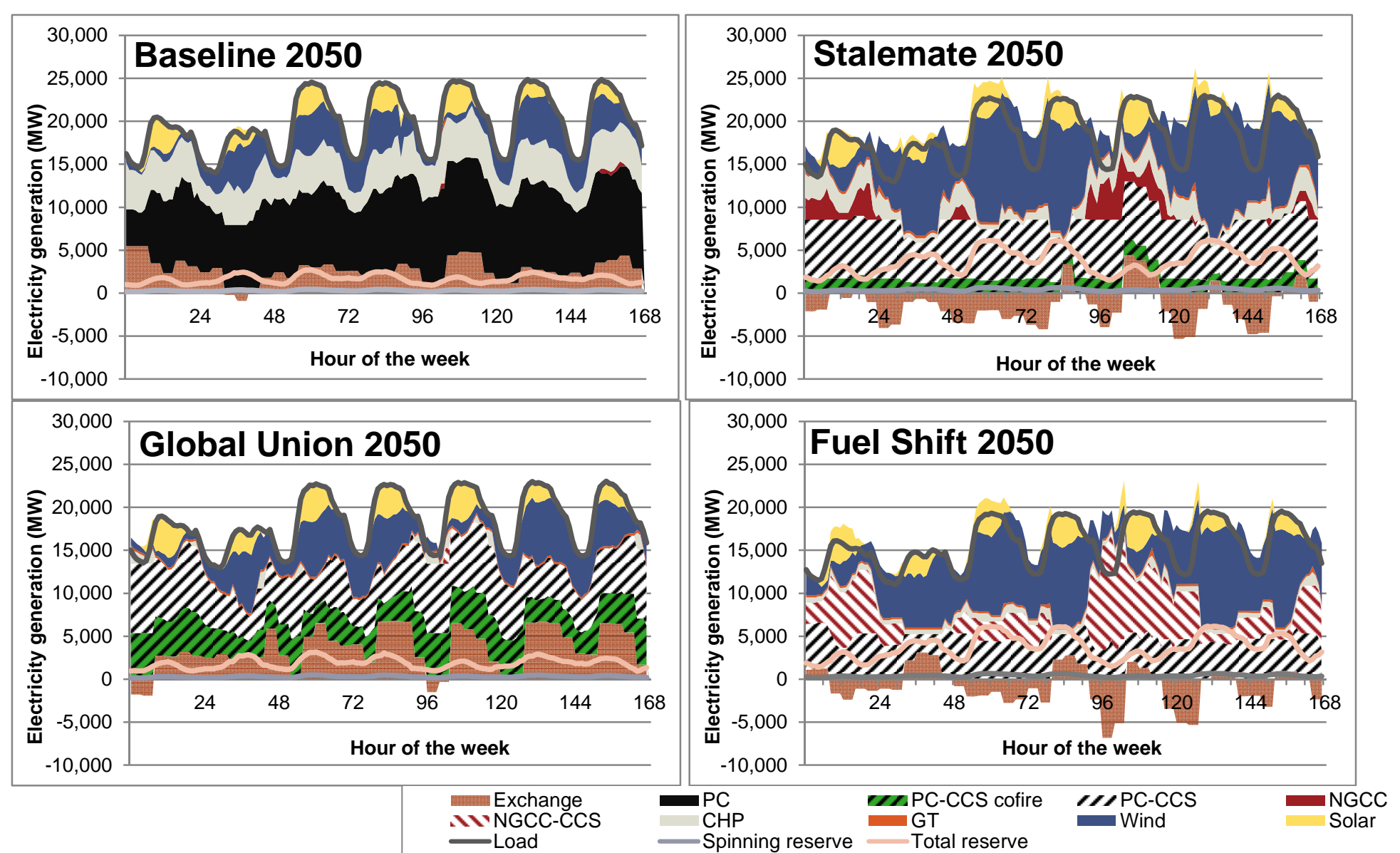

Figure 10: Power production in week 21 for the 2050 scenarios 


\subsection{Profitability of power plants}

A post analysis is performed to determine the profitability of power plants based on the current energy-based market design. The performance per unit type is shown in Table 10, and a detailed profitability overview is shown in Table 11 for the same generators as in Table 9. Again, these generators are the most recent and profitable within their class.

Nuclear and new solid-fuel fired power plants form the backbone of the power system in all scenarios, in terms of power production (capacity factors $>80 \%$ ) and spinning reserve provision ( $50 \% \pm 20 \%$ of all spinning reserves). This does not guarantee economic operation: electricity prices have to be sufficiently high (>75€/MWh for PC-CCS) to recoup the initial investment within 25 years. Older solid-fuel fired power plants have a similar role, but with lower capacity factors, and longer payback times.

The situation for new NGCC(-CCS) plants is generally uneconomic because their capacity factors are low, and because their profits are too small. NGCC(-CSS) generators are often the price setters: between $60-80 \%$ of the hours in all ' 50 scenarios, except for $20 \%$ in the Fuel Shift scenario. Thus, their short-run profits are therefore only slightly positive, which is not enough to cover the fixed O\&M costs. NGCC(-CCS) plants supply hourly reserves, the revenues of which could improve the business case, but the model does not remunerate for these. Older NGCC capacity has very low capacity factors in all scenarios, and should probably be decommissioned.

Despite their small capacity in most scenarios, gas turbines play an important role in all scenarios by supplying spinning reserves (10-30\% in '50 scenarios). More importantly, they supply sub-hourly reserves ( $55 \% \pm 15 \%$ of these reserves in the ' 50 scenarios). They are the most important source of sub-hourly reserves, together with $\mathrm{CHP}$ generators (if these are available in the scenario). Because gas turbines are the price setters whenever they run, they do not post short-term profits, and run at a loss.

Table 10: Performance of power plants types per scenario

\begin{tabular}{|c|c|c|c|}
\hline Unit type & Role of generator per scenario & $\begin{array}{l}\text { Reserve capacity provision } \\
\text { per unit [\% of unit capacity] }{ }^{a}\end{array}$ & 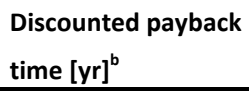 \\
\hline NUC & All ‘30: base-load (CF: 95\%) & SR: All '30: $4 \%$ & $\begin{array}{l}\text { GU'30: }>50 \\
\text { All others: } 20-30\end{array}$ \\
\hline $\begin{array}{l}\mathrm{PC}(-\mathrm{CCS}) \\
\text { (old) }\end{array}$ & $\begin{array}{l}\text { BL, GU'50, FS'50: mid-merit (CF: } 50-75 \% \text { ) } \\
\text { SM, GU'30, FS'30: base-load (CF: } 75-90 \% \text { ) }\end{array}$ & $\begin{array}{l}\text { SR: FS'50: } 8 \% \text {. } \\
\text { All others: } 4-6 \%\end{array}$ & $\begin{array}{l}\mathrm{BL}, \mathrm{SM}^{\prime} 50: 10-20 \\
\text { All others: }>50\end{array}$ \\
\hline $\begin{array}{l}\mathrm{PC}(-\mathrm{CCS}) \\
(\text { new })^{\mathrm{c}}\end{array}$ & All: base-load (CF: $80-95 \%)$ & $\begin{array}{l}\text { SR: BL'50: } 7 \% . \\
\text { All others: } 4-5 \%\end{array}$ & $\begin{array}{l}\mathrm{BL}, \mathrm{SM}^{\prime} 50: 7-10 \\
\mathrm{FS}^{\prime} 30: 34-40 \\
\text { All others: }>50\end{array}$ \\
\hline $\begin{array}{l}\text { NGCC(-CCS) } \\
\text { (old) }^{c}\end{array}$ & All: Peak generator (CF: 0-10\%) & SR: All: 0-3\% & All: $>50$ \\
\hline $\begin{array}{l}\text { NGCC(-CCS) } \\
(\text { new })^{c}\end{array}$ & $\begin{array}{l}\text { BL, GU: peak load (CF:10-25\%) } \\
\text { SM: mid-merit (CF:15-40\%) } \\
\text { FS: base-load (CF: } 65-80 \%)^{d}\end{array}$ & $\begin{array}{l}\text { SR: SM'50, FS: } 1-5 \% \\
\quad \text { All others: } 0-2 \% \\
\text { Important source of hourly } \\
\text { reserves }\end{array}$ & $\begin{array}{l}\mathrm{FS}^{\prime} 30: 42->50 \\
\text { All others: }>50\end{array}$ \\
\hline GT & All: Peak / mid-merit (CF: 20-30\%) & $\begin{array}{l}\text { SR: BL'50 4\%. } \\
\quad \text { All others: } 9-10 \% \\
\text { Main source of sub-hourly } \\
\text { reserves }\end{array}$ & All: $>50$ \\
\hline $\mathrm{CHP}^{\mathrm{e}}$ & $\begin{array}{l}\text { BL, SM, GU'30, Peak/mid-merit (CF: } 10- \\
50 \%) \\
\text { FS, GU'50: Peak-load (CF: 0-20\%) }\end{array}$ & $\begin{array}{l}\text { SR: All: } 0-10 \% \\
\text { Important source of sub- } \\
\text { hourly reserves. }\end{array}$ & Very diverse $^{f}$ \\
\hline
\end{tabular}

Abbreviations: BL - Baseline, SM - Stalemate, GU - Global Union, FS - Fuel Shift, CF - Capacity Factor, SR - Spinning Reserves.

a) The average yearly provision of spinning reserves (SR) as a percentage of unit capacity. Note that units can deliver up to $10 \%$ of their capacity as spinning reserve.

b) Based on a discount rate of $7 \%$.

c) Old units have been built $\geq 20$ years ago; more recent units are labeled "new". Units remain in the generator mix until their technical lifetime has run out: 40 years for PC plants, and 30 years for NGCC plants.

d) In the FS2050 scenario, 3.9GW new NGCC-CCS capacity runs base-load (CF: 70-80\%), and 8.5 GW runs mid-merit (CF: 30-65\%).

e) For a description of heat demand modeling with the MARKAL and REPOWERS models, see Appendix A.

f) Depends on the CHP type, the heat demand and the fuel costs. 
Solar PV power generation is uneconomic in all scenarios: the construction of these installations is fully driven by governmental RES-targets. Wind power generation is economic in most scenarios: only in the Global Union scenarios the electricity prices are not sufficient to cover its investment costs.

Overall, the post-analysis shows that the payback time of base load generators is economic ( $<25$ years) in the Baseline, Fuel Shift and Stalemate 2050 scenarios and uneconomic (>25 years) in the other scenarios. More importantly, investments in all mid-merit and peak-load generators are uneconomic in all scenarios under the current market design. Therefore, 'the market' would not have invested in these generators, which would have made the power system incapable to supply sufficient power. Our results show that with the current market design, future power systems seem incapable of running profitably and reliably at the same time. New or additional market designs are needed in the power sector to enable high shares of intermittent renewable sources.

Table 11: Profitability of selected generators

\begin{tabular}{|c|c|c|c|c|c|c|c|c|}
\hline 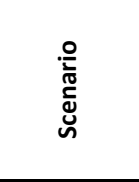 & 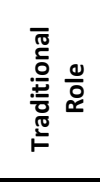 & 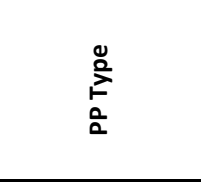 & 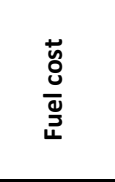 & 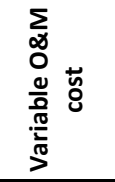 & 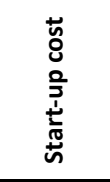 & 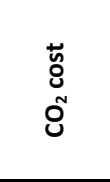 & 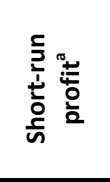 & 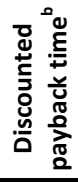 \\
\hline \multirow{5}{*}{$\begin{array}{c}\text { Baseline } \\
2030\end{array}$} & & & [M€/yr] & {$[\mathrm{M} € / \mathrm{yr}]$} & [M€/yr] & [M€/yr] & [M€/yr] & [yr] \\
\hline & Base & PC 2030 & 134 & 16.2 & 0.9 & 0 & 172 & 9 \\
\hline & Mid & NGCC 2030 & 30 & 0.5 & 1.5 & 0 & 9 & $>50$ \\
\hline & Peak & $\mathrm{GT}$ & 19 & 0.2 & 0.0 & 0 & -4 & $>50$ \\
\hline & RES & Wind & - & - & - & - & 1225 & 26 \\
\hline \multirow{4}{*}{$\begin{array}{c}\text { Baseline } \\
2050\end{array}$} & Base & PC 2040 & 145 & 16.4 & 0.2 & 0 & 193 & 7 \\
\hline & Mid & NGCC 2040 & 46 & 0.7 & 1.4 & 0 & 21 & $>50$ \\
\hline & Peak & GT & 10 & 0.1 & 0.1 & 0 & -2 & $>50$ \\
\hline & RES & Wind & - & - & - & - & 1369 & 12 \\
\hline \multirow{4}{*}{$\begin{array}{l}\text { Stalemate } \\
\qquad 2030\end{array}$} & Base & PC-CCS 2030 & 207 & 25.9 & 0.6 & 18 & 125 & $>50$ \\
\hline & Mid & NGCC 2010 & 98 & 1.9 & 4.7 & 26 & 26 & $>50$ \\
\hline & Peak & GT & 21 & 0.2 & 0.0 & 6 & -6 & $>50$ \\
\hline & RES & Wind & - & - & - & - & 2079 & 17 \\
\hline \multirow{4}{*}{$\begin{array}{c}\text { Stalemate } \\
2050\end{array}$} & Base & PC-CCS 2040 & 194 & 25.8 & 0.4 & -54 & 282 & 7 \\
\hline & Mid & NGCC 2040 & 110 & 1.8 & 3.8 & 87 & 8 & $>50$ \\
\hline & Peak & GT & 19 & 0.2 & 0.0 & 15 & -12 & $>50$ \\
\hline & RES & Wind & - & - & - & - & 4491 & 10 \\
\hline \multirow{3}{*}{$\begin{array}{l}\text { Global } \\
\text { Union }\end{array}$} & Base & PC-CCS 2030 & 175 & 26.1 & 0.3 & 14 & 82 & $>50$ \\
\hline & Mid & NGCC-CCS 2030 & 151 & 5.7 & 3.0 & 8 & 20 & $>50$ \\
\hline & Peak & GT & 14 & 0.2 & 0.0 & 8 & -8 & $>50$ \\
\hline 2030 & RES & Wind & - & - & - & - & 1575 & 36 \\
\hline \multirow{2}{*}{ Global } & Base & PC-CCS 2040 & 217 & 23.4 & 2.4 & -148 & 54 & $>50$ \\
\hline & Mid & NGCC-CCS 2030 & 25 & 1.2 & 3.7 & 3 & 10 & $>50$ \\
\hline Union & Peak & $\mathrm{GT}$ & 10 & 0.2 & 0.0 & 14 & -15 & $>50$ \\
\hline \multirow[t]{2}{*}{2050} & RES & Wind & - & - & - & - & 611 & $>50$ \\
\hline & Base & PC-CCS 2030 & 169 & 27 & 0.3 & 53 & 134 & 22 \\
\hline \multirow{3}{*}{$\begin{array}{l}\text { Fuel Shift } \\
\qquad 2030\end{array}$} & Mid & NGCC-CCS 2030 & 191 & 4 & 3.3 & 17 & 61 & 19 \\
\hline & Peak & GT & 17 & 0 & 0.0 & 14 & -10 & $>50$ \\
\hline & RES & Wind & - & - & - & - & 2034 & 18 \\
\hline \multirow{4}{*}{$\begin{array}{l}\text { Fuel Shift } \\
2050\end{array}$} & Base & PC-CCS 2040 & 106 & 27 & 0.6 & 84 & 34 & $>50$ \\
\hline & Mid & NGCC-CCS 2040 & 145 & 4 & 2.7 & 27 & 3 & $>50$ \\
\hline & Peak & GT & 10 & 0 & 0.0 & 22 & -19 & $>50$ \\
\hline & RES & Wind & - & - & - & - & 2913 & 25 \\
\hline
\end{tabular}

a) The short term profit is calculated by deducting the fuel, variable $\mathrm{O} \& \mathrm{M}$, start-up and $\mathrm{CO}_{2}$ costs from the annual revenue in the current market design . No electricity price mark-up or revenues from supplying reserves are included.

b) The discounted payback time is equal to the year when the cumulative sum of discounted short-term profits and fixed O\&M costs equals the initial investment costs. A discount rate of $7 \%$ is used. 


\subsection{Sensitivity analysis}

A sensitivity analysis was performed with the REPOWERS model for the seven parameters, shown in Table 12 . We assessed the effect on the electricity price, generator shares, average efficiency reduction and international exchange of electricity. The fuel prices strongly affect the electricity price, and lower fuel prices cause a swap from PC to NGCC generators [Figure 11]. This generally increases the average reduction in power plant efficiency, as NGCC part-load operation is less efficient. Variations in the biomass price do not affect the results.

An increased $\mathrm{CO}_{2}$ price reduces PC generation and increases NGCC generation. Moreover, electricity prices increase. The opposite effect applies for the Global Cooperation scenario, as its PC emissions are lower than NGCC emissions due to biomass co-firing.

An increase in minimum load levels results in a slight shift from PC to NGCC capacity [Figure 11]. As a result, the electricity prices increase somewhat. The efficiency penalty decreases, as the minimum load limits the most inefficient operation at very low loads.

The ramp rate of power plants only slightly affects the indicators (0-2\% variation). Also, an increased reserve size has a minor impact: $1 \%$ increase in electricity price, up to $3 \%$ more NGCC generation. The reverse trend applies for a smaller reserve size.

The effect of no exchange on the electricity price is a small decrease in efficiency reduction [Figure 11]. It results in both more PC and NGCC generation in the Global Union and Fuel Shift scenarios. No remuneration for negative emissions only affects the Global Union scenario. Especially the effect on the electricity price is steep. The reduction in efficiency becomes smaller as PC-CCS plants are not the cheapest option by default anymore, so NGCC generation displaces their most inefficient operation.

Table 12: Sensitivity analysis parameters

\begin{tabular}{lcc}
\hline Parameter & Range varied & Range based on \\
\hline All fuel prices & $\pm 50 \%$ & Range in Table 2 \\
Biomass price & $\pm 50 \%$ & Same as for fuel prices \\
$\mathrm{CO}_{2}$ price & $\pm 50 \%$ & Uncertainty [27] \\
Minimum load level of power plants & $\pm 50 \%$ & Range in Table 5 \\
Ramp rate of power plants & $\pm 50 \%$ & Range in Table 5 \\
Reserve size of system & $\pm 50 \%$ & Reported range [8] \\
No international exchange & $\mathrm{n} / \mathrm{a}$ & Assumption \\
No remuneration for negative emissions $\left(\mathrm{no}-\mathrm{CO}_{2}\right)$ & $\mathrm{n} / \mathrm{a}$ & Assumption \\
\hline
\end{tabular}

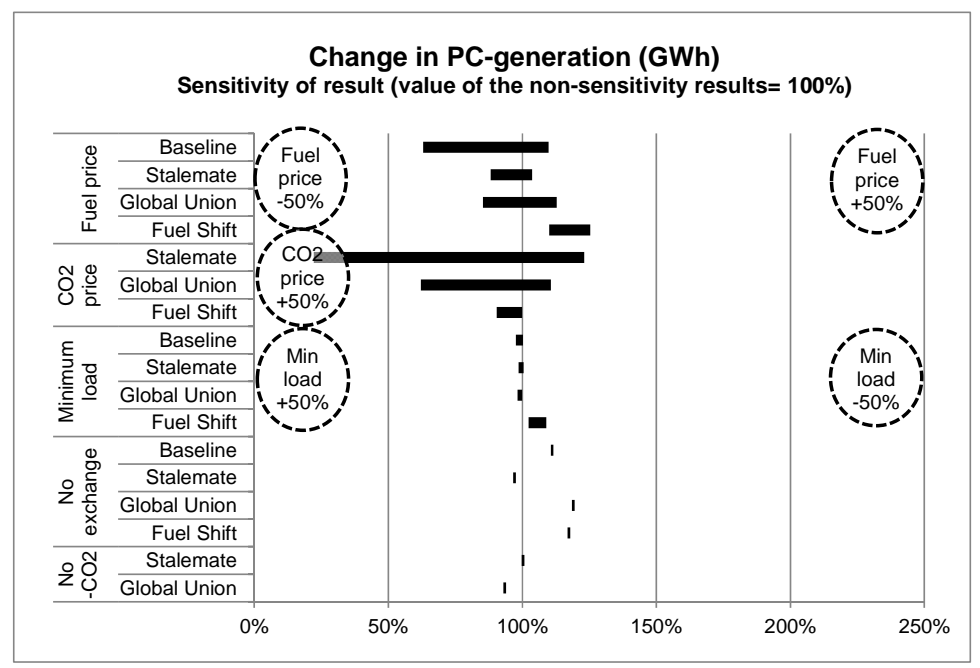




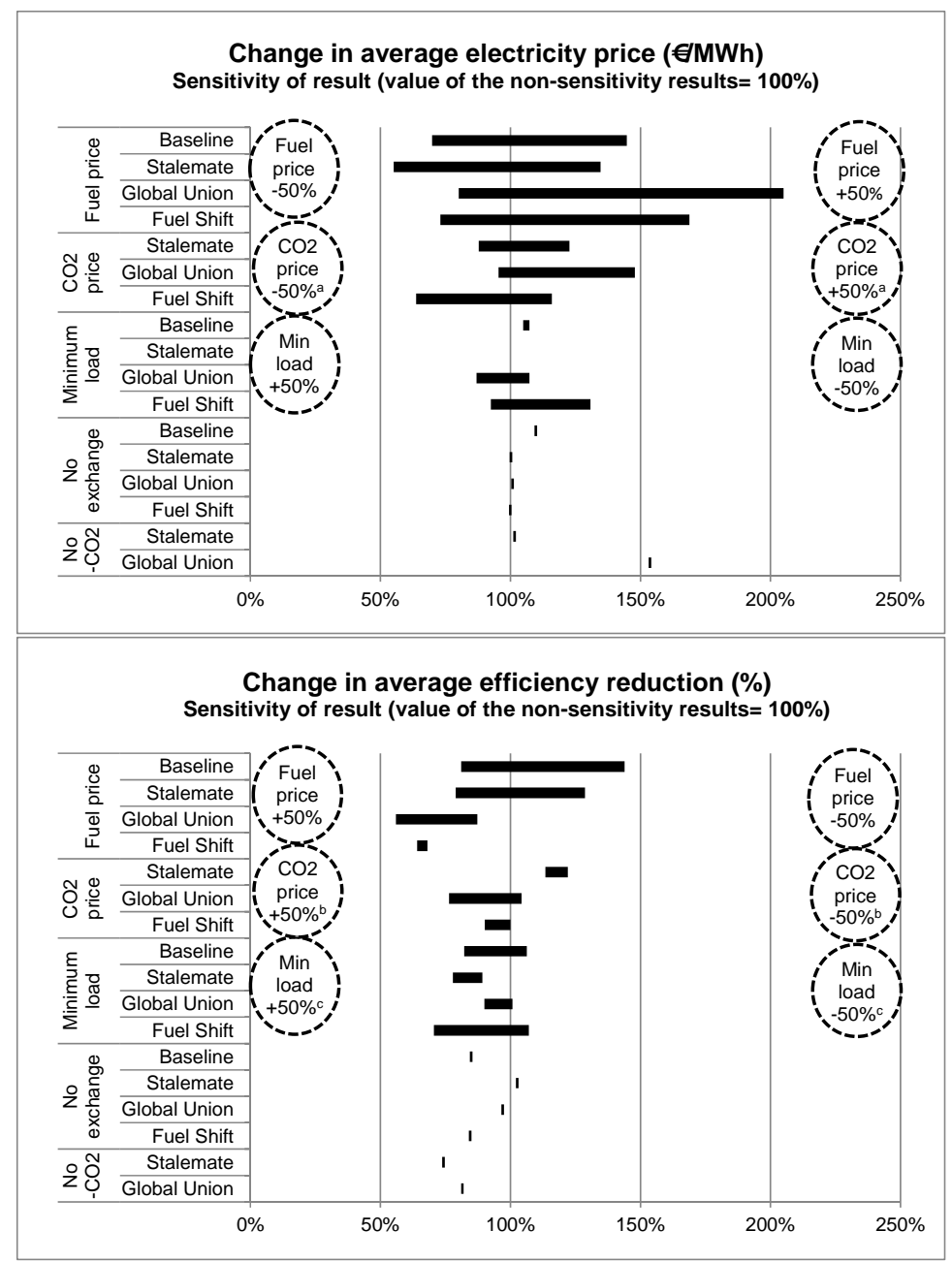

Figure 11: Selected sensitivity analysis outcomes.

a) In the Global Union scenario, the labels are reserved (higher electricity price at lower $\mathrm{CO}_{2}$ price).

b) In the Global Union scenario, the labels are reserved (efficiency reduction at lower $\mathrm{CO}_{2}$ price).

c) In the Stalemate and Fuel Shift scenarios, the labels are reversed ( the smallest efficiency reductions are seen with increased minimum load levels).

\section{Discussion}

\section{Soft-link approach}

To the knowledge of the authors, only Deane et al. also soft-linked power system optimization and UCED models [24]. In fact, their observations are in line with those of this study. The calculated generation by the UCED model and optimization model are largely the same. Moreover, our UCED model also reports higher wind-curtailment, and higher capacity factors for gas turbines than the optimization model.

A mismatch exists between the models: the uneconomic payback times calculated with the REPOWERS model do not warrant the large investments in new capacity projected by MARKAL. Thus, there is a 'missing money' problem: not enough money is made to warrant new investments under the current market design. The simulated electricity prices per MWh cover only $84 \%$ ( $\pm 30 \%$ ) of the total power system costs per MWh. Part of the missing $16 \%$ could be from reserve markets, for which the REPOWERS model does not account, and the remaining money would have to be made by other means, e.g. alternative market designs (e.g. a capacity market) or policy support. It should be noted that future fuel prices and investment costs strongly affect the payback times, so future analysis should address this. 


\section{Flexibility}

The literature review indicates that the operating flexibility can be improved, to the extent that coal/biomass-fired power plants are often flexible enough to accommodate for large changes in residual demand. However, when extra flexibility is implemented, operators could refrain from utilizing the improved start-up times and ramp rates, because they incur extra costs [60].

Moreover, it is currently unknown how variable $\mathrm{CO}_{2}$ flows from capture units can be handled by the transport and injection infrastructure at a national scale. Studies report that the variability can be handled when a single source and sink are connected by a pipeline, as long as the $\mathrm{CO}_{2}$ flow is heated during startup [102], and the $\mathrm{CO}_{2}$ flow does not become smaller than $20 \%$ of the rated volume [103].

\section{Potential improvements to the models}

Better demand patterns would improve the results. The electricity and heat demand profiles in this study are based on present-day profiles, which are extrapolated based on total projected electricity and heat demand. Yet, the profiles may significantly change in the future as a result of further electrification and energy efficiency measures. In addition, demand side management may better align electricity supply and demand in the future.

CHP generators also supply a significant amount of electricity ( $20 \%$ in the Baseline and Stalemate scenarios), because cost allocations to heat production lower their cost of electricity. Both models now use crude heat patterns for two aggregated sectors, for 3 season types. More detailed heat patterns could increase the variability of power production by CHP units, and therefore increase the need for flexibility in the system.

Only thermal and renewable generators can generate electricity and supply reserve capacity in our models. Other technologies could potentially also supply these (such as electricity storage [104], demand side management [55] and pumped hydro storage abroad [47]), which could reduce the overall investment and operational costs of the system.

The simulation of system reserves could be further improved in three ways. Firstly, the reserve sizes could be calculated specifically for the Netherlands, rather than basing them on approximations from other studies. Secondly, the provision of spinning reserves is currently capped at $10 \%$ of maximum capacity per unit, because deliveries of frequency reserves are capped. By separately modeling frequency and regulating reserves, the latter spinning reserves can be modeled without a cap. Thirdly, novel generation solutions could supply reserves, such as electricity storage, demand side management and wind power, which may be particularly beneficial in 'low load, high wind' situations.

\section{Coal/ biomass-fired power plants}

Our results show that biomass co-firing with $\mathrm{CCS}$ is promising in scenarios with high $\mathrm{CO}_{2}$ prices. The business case of this option may have benefited from three assumptions.

1) We assume that negative emissions generate $\mathrm{CO}_{2}$ credits that can be sold at the (high) $\mathrm{CO}_{2}$ price in the future. This is vital for the combined implementation of biomass and CCS $[105,106]$. Additionally, no feedback effects of 'negative emissions' on the $\mathrm{CO}_{2}$ price are accounted for. In the Global Union 2050 scenario, these may occur due to the large amount of stored biogenic $\mathrm{CO}_{2}$.

2) We assume that the performance of the pulverized coal fired power plants is not affected by biomass co-firing. However, co-firing of large shares ( $>30 \%)$ of biomass pellets may increase the investment costs by about $5-10 \%$, and reduce the net efficiency by about $1 \%$-point $[105,107]$. The exact effect is still unclear, and may be smaller when torrified pellets are used $[105,108]$.

3) Biomass co-firing requires large amounts of biomass: $350 \mathrm{PJ} / \mathrm{yr}$ in the Global Union 2050 scenario for the Netherlands. Studies indicate that the worldwide technical potential for biomass is large enough to supply these 
quantities $[109,110]$. If biomass supply is limited, it may be more profitable to use biomass in other sectors (e.g. industry, transport), reducing the amount available for the power sector.

On the contrary, two assumptions may have limited biomass utilization.

1) Only biomass co-firing in PC-power plants and biomass gasification in IGCCS are considered in this study. Inclusion of other biomass-fired power generation types (e.g. dedicated combustion and bio-CHP) could further increase biomass utilization.

2) The high future biomass prices of $8-9 € / G J$ that are used are at the upper range of projected future costs for (torrified) pellets (3-9€/GJ), because biomass markets are still immature $[30,111]$. Lower prices could increase biomass use, especially in combination with more biomass conversion technologies.

\section{Comparison to other studies}

The studies mentioned in the introduction do not report much on flexibility. This may be an indication that flexibility is not a major issue, which is in line with our findings. Whatever these studies mention on flexibility is largely comparable to our results. Similar to the Roadmap 2050 study by ECF, we conclude that the power plants are flexible enough, and that nuclear and coal-fired power plants maintain high capacity factors [3]. Both Bertsch et al. and this study report that the capacity factors of base-load and mid-load plants decrease over time when IRES penetration increases. Bertsch reports a larger average decrease in capacity factor of coal plants between 2030 and 2050: 36\%, compared to $8 \%$ in this study across all scenarios. [11]. Moreover, Bertsch concludes that the profitability of base-load plants is adequate, of mid-merit is break-even, and of peak-load is not sufficient. We report lower revenues for midmerit and peak-load capacity, potentially because we do not account for reserve revenues, and because we have more base-load capacity, shifting the merit order position of mid-merit power plants.

\section{Conclusion}

A novel modeling toolbox is developed in this study, which comprises a soft-linkage of a power system optimization model (MARKAL-NL-UU) and a power system simulation model (REPOWERS). This toolbox minimizes the total system costs by making both long term (investment) and short term (commitment and dispatch) decisions whilst explicitly accounting for flexibility constraints. Thus, scenarios can be designed and simulated in a consistent way to explore (the transition to) future scenarios. New market designs (e.g. capacity markets) and novel power generation solutions (e.g. demand side management, electricity storage, and high shares of renewable sources) can be included in these scenarios.

We use the toolbox to evaluate the technical and economic feasibility of power plants with CCS for four Dutch power system scenarios with stringent $\mathrm{CO}_{2}$ emission reduction targets. First, the power generation mixes are projected with MARKAL, which have intermittent renewable shares of $14-42 \%$.

Next, the technical performance was analyzed with REPOWERS, showing that enough flexibility is present in future power systems to accommodate renewables, due to advances in power plants flexibility. Post-combustion capture units will probably not reduce the flexibility of their base power plants, so power plants with CCS generate large shares of power (23-62\%) in the low-carbon scenarios. What is more, (partially) biomass-fired power plants with CCS can realize negative $\mathrm{CO}_{2}$ emissions, which can compensate emissions elsewhere. Overall, power system emissions are reduced by $87-130 \%$ in the low-carbon scenarios compared to the Baseline in 2050.

Future low-carbon power systems can be run reliably and with low emissions, when $130 \%$ of peak capacity is present (as enforced by MARKAL), and if renewable generation can be curtailed (sometimes strongly: 1.6-14\% of annual wind production in low-carbon scenarios). 
The variability of residual load is the main driver for the efficiency reduction of thermal power plants of 0.6-1.6\%. The efficiency reduction is driven by (in order of decreasing importance): absolute interconnection flows $\left(r^{2}=0.67\right)$, the volume of centralized electricity production $\left(r^{2}=62\right)$, IRES power production $\left(r^{2}=0.55\right)$ and the variability of load itself $\left(r^{2}=0.38\right)$. Hence, IRES are not the main driver of power plant efficiency reductions. Between scenarios, the variability changes by $\pm 40 \%$, and the number of startups increases by $45-60 \%$ in low-carbon scenarios compared to the Baseline, especially for NGCC-plants (+150\% starts, $+50 \%$ variability).

Lastly, the economic feasibility is determined with a post-analysis, based on the current market design that remunerates per MWh generated. The low-carbon scenarios are on average $17 \%( \pm 15 \%)$ more expensive per MWh generated. All scenarios experience a "missing money" problem with this market design: the price received per MWh is on average only $84 \%$ ( $\pm 30 \%$ ) of the total generation costs per MWh. Specifically, this means that mid-merit and peak-load generators do not earn back their investment costs in any of the scenarios, and base-load generators (with CCS) only in half the scenarios.

As a result, less capacity will be installed in practice than projected with the optimization model, which will reduce the reliability of the power system. With the current energy-based market design, future power systems therefore seem incapable of running profitably and reliably at the same time. New or additional market designs are needed in the power sector to enable high shares of intermittent renewable sources. Potential market designs include capacity, flexibility and reserve markets, which directly remunerate these power system services.

These power system services could potentially be supplied more cost-effectively by novel power generation solutions such as demand side management and electricity storage than by thermal backup capacity. For example, NGCC plants make up a relatively large part of the total system costs in all scenarios (2-5 times the average cost per MWh), because NGCC capacity is hardly used (capacity factors of $0-25 \%$ ).

Recommendations for future research:

- Quantification of profitability of power plants in future power systems for different market designs.

- Evaluation of cost-effective deployment of novel power generation solutions in future power systems, such as DSM and electricity storage.

- $\quad$ Projecting future demand patterns and identification with shares of demand are suitable for demand side management.

- $\quad$ Performing a detailed techno-economic analysis on the application of bio-energy with CCS in the power sector.

\section{Acknowledgements}

This research was carried out in the context of the CATO-2-program. CATO-2 is the Dutch national research program on $\mathrm{CO} 2$ Capture and Storage. The program is financially supported by the Dutch government (Ministry of Economic Affairs) and the CATO-2 consortium parties. The authors would like to thank the power plant experts for their input, Joost van Stralen and Özge Özdemir for their technical support and Jos Sijm for his comments. 


\section{Appendix A: description of MARKAL-NL-UU and REPOWERS models}

\section{MARKAL-NL-UU model}

The MARKAL (MARKet ALlocation) model is a bottom-up linear optimization tool. It optimizes the use of energy sources, energy carriers, and transformation technologies to fulfill energy demand of selected sectors at the lowest cost. The model selects energy transformation technologies from a portfolio of options and is subject to user-defined constraints, such as the maximum allowed $\mathrm{CO}_{2}$ emissions $[18,19]$

The MARKAL-NL-UU model is a version of the MARKAL model that optimizes the energy system of the Netherlands. In this study, it is used to calculate the optimal (least-cost) electricity mix until 2050, with a time step of 5 years. For these years, 9 time slices are calculated per year and two types of heat demand are distinguished: must-run demand and flexible demand [20].

Input data consist of fuel prices [Table 2], the techno-economic parameters of the current Dutch centralized power plant portfolio (based on the same dataset as used in [26]), as well those of future power plant technologies [Table 3 and 4].

Output data include the generator mix, the amount of electricity generated per generation technology and the national $\mathrm{CO}_{2}$ price. This price is determined by the shadow price of the $\mathrm{CO}_{2}$ emission constraint, and used as a proxy of the EU ETS carbon price

\section{Assumptions}

- The model only considers power production in the Netherlands; interconnections are not included.

- Co-firing of biomass can be done up to 30\% in 2030 and 50\% in 2050 [105].

- To maintain system reliability, the model will always require $130 \%$ of the annual peak load as installed capacity.

- $15 \%$ of offshore wind, $10 \%$ of onshore wind and $5 \%$ of solar PV capacity is treated as firm capacity that contributes to the reliability of the system.

- Heat demand is simulated, but not included in the results. Heat demand is fulfilled by either CHP units or auxiliary boilers.

\section{REPOWERS model}

REPOWERS is a unit commitment and economic dispatch model based on Lagrangian Relaxation. Its objective is to minimize the short-term costs of power generation whilst meeting power demand and accounting for the technical constraints of power plants.

The REPOWERS model is largely based on the description of Virmani et al. [112], only the implementation of the spinning reserves is based on Wood [113]. The model uses Lagrangian relaxation, a computational approach in which the constraints are relaxed by formulating them as sub-problems and introducing a Langrangian multiplier. By iteratively solving the objective function and the sub-problems, optimal dispatch can be calculated efficiently [114].

REPOWERS calculates the optimal hourly dispatch per week, for 365 days per year. For every hour, power generation has to equal the sum of domestic demand and imports/exports (where imports are considered negative load). Centralized units are modelled individually, and decentralized units, (many of which CHP units), are modelled in an aggregated way with 12 separate unit categories. Each of these categories is treated as a separate unit. The model 
includes quadratic part-load efficiency curves for all thermal units, and accounts for the following flexibility constraints:

1) Each plant has a minimum up and down time (in hours).

2) Maximum ramp up and ramp down rates (defined in $\mathrm{MW} /$ hour).

3) Minimum load level (in MW).

4) Start-up and shut-down costs (in $€ /$ event).

For REPOWERS, a fixed maximum amount of heat can be generated by CHP units per hour depending on the season. When heat is generated, part of the fuel and emission costs are allocated to heat production by correcting the electric efficiency of the CHP plant with the formula $\eta_{\text {corrected }}=\eta_{\mathrm{e}} /\left(1-\left(\eta_{\text {th }} / \eta_{\text {boiler }}\right)\right)$. A boiler efficiency of $95 \%$ is assumed for low quality heat from a heat engine, and a boiler efficiency of $90 \%$ is assumed for high quality heat from the other types of installations [115]. It is assumed that CHP units are equipped with auxiliary boilers, so none of the generators are truly must-run.

Power generation from wind and solar PV power generators is based on exogenous production profiles. The model can curtail wind power production in order to maintain the balance between generation and load, and to ensure sufficient spinning reserves are available.

Imports/exports are included by calculating the residual supply curve of the foreign countries directly interconnected to the Netherlands, i.e. Belgium, Denmark, Germany and the U.K. The residual load has to be at least $1 \mathrm{MW}$; negative residual load is assumed to be curtailed. Foreign generator mixes are based on PRIMES projections and national policy goals. A cost-supply curve is constructed for each of these countries, where marginal costs of each unit category are calculated based on the techno-economic specifications that are also used in the MARKAL model. The supply curve is assumed to be continuous rather than stepwise. The residual supply curves include exchange with the Netherlands, and are iteratively calculated. International exchange of power is assumed to take place in trading-blocks of 4 hours, for which a surcharge of $€ 5 / \mathrm{MWh}$ is incurred.

Spinning reserves are modelled as capacity that can be made available to the system within 15 minutes. Spinning reserve requirements can be split between online units and offline units. In REPOWERS only supply by online units is considered. When the spinning reserve requirement is violated, the output of the most expensive unit in operation is reduced until it reaches its maximum possible contribution (being the smaller of either $10 \%$ of the nominal capacity or the maximum ramp up/down capacity in 15 minutes). Next, the output of the one-but most expensive unit is reduced, and so forth until the requirement is met. More expensive units cover the supply deficit that is created because of this procedure, increasing the total system cost and the electricity price.

The model has been successfully validated against ECN's POWERS model for the year 2006, and against a dynamic programming model for a fictional power system for the same year. Also, it has been used for the ITM project [116]

\section{Input data}

The same efficiencies and variable O\&M costs are used as in the MARKAL model. Moreover, a set of standardized flexibility-parameters was composed for the model per generation technology and decade of construction [Table 5]. Power plant outage patterns are determined exogenously based on historical outage statistics.

The load and RES-E production patterns are corrected for projected future developments for both the Netherlands and neighboring countries. An exogenous curtailment step is performed for the Netherlands, to ensure a minimum residual load of $4 \mathrm{GW}$ to facilitate model solving.

\section{Assumptions}

- The model only simulates the provision of reserve capacity, not the actual dispatch of reserve capacity.

- The uncertainty in production patterns of intermittent renewable sources is assumed to be covered by increased reserves sizes compared to situations without renewable energy sources.

- Renewable sources have an early position in the merit order, but no priority over thermal power generators. 


\section{Appendix B: description of flexibility parameters}

\section{Minimum load}

The minimum load level is the lowest level at which a power plant can operate for an extended time whilst meeting emission limits, expressed as a percentage of the maximum capacity. The lowest minimum load levels are projected for nuclear and PC power plants. An overview is provided in Table 5. The $3^{\text {rd }}$ generation nuclear power plants have been designed for load levels as low as $25 \%$ of maximum load [117]. PC power plants have seen improvements to the main bottlenecks, which include the firing system, steam turbine and especially the boiler. Current and future improvements include indirect firing, rifled boiler tubing and low-load circulation systems [52,118-120]. The minimum load level of an IGCC is mainly limited by the gasifier and Air Seperation Unit (ASU), which can be turned down to about $50 \%$ and $70 \%$ of maximum load respectively [54]. At lower loads gasifiers experience problems with sustaining the protective slag layer, and the ASU contains a compressor that cannot run at lower loads [61]. Installing multiple gasifiers/ASU trains will reduce the minimum load level of the plant, albeit at extra investment costs. If the plant is designed as a polygeneration plant with multiple outputs (i.e. electricity, $\mathrm{H}_{2}$, FT-liquids, and/or methanol), switching outputs will improve the flexibility in electricity generation [61]. The combined cycle is not expected to be a bottleneck for the minimum load level [54]. As IGCCS power plants are not main-stream, there is more uncertainty associated with future developments.

The minimum load levels of NGCC and OCGT plants are not set by the technical minimum load but by emission limits, as $\mathrm{CO}$ and $\mathrm{NO}_{\mathrm{x}}$ emission levels increase considerably at low loads [54]. Currently, the $100 \mathrm{mgNO} / \mathrm{Nm}^{3}$ emission limit is met at NGCC load levels of $>45 \%$, and it is expected that through incremental improvements it can be reduced to $40 \%$ by 2020 [121]. In time, the use of a parking-load level may become mainstream and reduce the minimum load even further, as shown by the $20 \%$ minimum load level of the Alstom KA26 NGCC plant [58], and it is expected that these improvements will become widely adopted in the future. The minimum load level of an OCGT is slightly lower than that of an NGCC based on the same turbine type [58,122], but the wider variety of OCGT types results in a larger uncertainty.

The addition of a $\mathrm{CO}_{2}$ capture unit does not appear to affect the minimum load level, as long as parallel compressor trains are present. Two detailed studies considered a PC plant with CCS in detail: a FEED study by E.ON reports a minimum capture plant operating level of $25 \%$, and a study by Foster Wheeler identified the absorber as the bottleneck with an operating level of $30 \%$ of full load [54,102]. More global studies also report that the capture unit does not have an impact $[53,123]$.

\section{Ramp rate}

The ramp rate is the average speed at which power output can be increased or decreased between the minimum and maximum load levels, expressed as a \% of the maximum capacity per minute. Ramping causes the temperature of power plant components to change, resulting in thermal stress that reduces the lifetime of the power plant. As a result, ramping rates are typically lower in practice than the maximum achievable ramp rates, because the maximum rates put a larger strain on the equipment. The selected values shown in Table 5 are therefore conservative estimates based on literature.

Nuclear power plants are projected to be of the $3^{\text {rd }}$ generation until at least 2040 [7], which have ramp rates of $5 \% / \mathrm{min}$ [117]. The ramping speed of PC plants is mainly determined by the boiler, and to a smaller extent by the steam turbine [96]. Thinner components reduce the thermal stress on these components, which can be achieved with once-through boilers (which have thinner walls than drum type boilers), the use of better materials and an increase in the number of lines in the boiler. Also, better monitoring of the steam turbine can provide operators with better information about its ramping capabilities [52,120,124]. Ramp speeds of an IGCC plant are primarily limited by the gasifier, but the ASU is also relatively inflexible. The IGCC power island has flexible characteristics comparable to a NGCC plant. The NGCC ramp rate is mainly limited by the steam cycle, as gas turbines can ramp quickly [59]. Similar 
improvements as for PC power plants can increase the ramp speed of the steam cycle. Moreover, the use of attemperators can partly decouple the gas and steam cycles, allowing the gas turbine to ramp more quickly [54]. Auxiliary firing of natural gas in the heat recovery steam generator can boost power production, but comes at an efficiency penalty [59].OCGT power plants have the highest ramp rates because of the lack of thick-walled components and inertia in the system. The most flexible OCGT plants feature blade cooling by air instead of steam, but this comes at an efficiency penalty [66].

The addition of a $\mathrm{CO}_{2}$ capture unit will probably not affect the ramp rate. Four studies simulated the capture unit (or specific components of it), and showed that these can quickly adjust to a changing flue gas flow whilst maintaining a target capture rate (e.g. 95\%) [125-128]. Moreover, A FEED study for a PC power plant with CCS confirms that its ramp rate is probably not affected by the capture unit [102].

\section{Start-up time}

The start-up time is defined as the time it takes from turn-on to reach the minimum load level. An overview is provided in Table 5. One of the most important start-up processes is heating up the power plant, so the start-up time is highly dependent on whether the unit is in a hot, warm, or cold condition, based on how much time has elapsed since its last shutdown. As with ramping, thermal stress is the main limiting factor for fast start-ups, so measures that increase the ramp speed also shorten the start-up time. In the REPOWERS model runs, hot start-ups are most common, so the hot start-up time is used as the default startup time in the model.

Start-up times of future $3^{\text {rd }}$ generation nuclear power plants are assumed to remain the same as the current state-ofthe-art start-up time.

The start-up procedure of pulverized coal power plants consists of: 1) establishing boiler circulation, 2) igniting the burners 3) warming up the boiler, during which steam is bypassed to the condenser, and 4) starting the steam turbine, where the third step takes most time [54]. Future improvements include an earlier turbine start with relatively cold steam, and improved start-up procedures [129].

The warm start-up procedure of an IGCC plant consists of 1) Coal and oxygen are fed to the gasifier; 2) Produced syngas is led through treating facilities and flared; 3) Adjusting syngas conditions to NGCC specifications; and 4) Start NGCC or switch from natural gas firing to syngas firing [130]. Start-up times of $6 \mathrm{~h}$ and $6-8 \mathrm{~h}$ are reported for current IGCC plants $[54,130]$. The ASU and gasification island are both limiting factors with start-up times of approximately 6 hours. Future improvements are dependent on the R\&D effort.

The start-up of a NGCC consists of 1) gas turbine start-up, 2) HRSG \& steam turbine start-up, and 3) ramp up of the steam turbine. These three steps take around 30, 40 and 20 minutes, respectively [54]. Three improvements have been suggested to shorten start-up times: using a once-through HRSG, keeping the steam cycle in a hot, operationready mode, and optimizing the start-up procedure, for example by using attemperators that allow the gas cycle and steam cycle to be operated independently [131].

Gas turbines can start up rapidly: their start up procedure consists of 1) purging the turbine by revving up without firing, 2) revving down the turbine, 3) igniting the combustor and 4) warming up the turbine whilst ramping up [132].

The addition of a capture unit could affect the start-up time of power plants, because the stripper of the capture unit will have to warm up. From the moment that steam is available for heating, the start-up of the capture unit may take 45 minutes ([127], or 2-4 hours [54]. This may especially be a problem for NGCC power plants, because steam is not immediately available during its start-up. Options to reduce the capture unit start-up time are 1) initial venting, 2) heat supply by an auxiliary boiler, or 3) storage of rich amines until the stripper is at operating temperature [54,133]. 


\section{Start-up cost}

Startup costs consist of a number of components. Depending on the definition used, only the direct costs are included (the narrow definition) or also indirect costs (the broad definition), as shown in Table B.1. While the direct costs can be easily determined based on the fuel use and the manufacture-defined effect on maintenance and lifetime, the indirect costs are harder to quantify. In the past, Aptech and EPRI have tried to quantify these with a bottom-up and a top-down approach, respectively, but the results were rather power plant specific (Aptech), or had issues with the data quality (EPRI) [134,135]. The range of cost estimates is also sizable, especially for NGCC plants. No universal method currently exists to determine the start-up costs in the broader sense [136]. We distinguish three kinds of start-ups: hot, warm and cold, for power plants that have been switched off for less than 12 hours, between 12 and 72 hours and more than 72 hours, respectively [137]

Table B.1: Overview and estimate of cost components of hot startup costs.

\begin{tabular}{|c|c|c|c|c|}
\hline & $\begin{array}{c}\text { Narrow } \\
\text { definition }\end{array}$ & $\begin{array}{c}\text { Broad } \\
\text { definition }\end{array}$ & $\begin{array}{c}P^{\mathbf{b}} \\
€ / \mathrm{MW}_{\text {installed }}\end{array}$ & $\begin{array}{c}\text { NGCC }^{\mathbf{C}} \\
€ / \mathrm{MW}_{\text {installed }}\end{array}$ \\
\hline Maintenance and capital & $\mathrm{x}$ & $\mathrm{X}$ & 76 & 116 \\
\hline Forced outage $^{a}$ & & $\mathrm{x}$ & 36 & 30 \\
\hline Start-up fuel & $\mathrm{x}$ & $\mathrm{x}$ & 12 & \multirow{3}{*}{9} \\
\hline Auxiliary power & & $\mathrm{x}$ & 6 & \\
\hline Water chemistry costs and support & & $\mathrm{X}$ & 1 & \\
\hline Efficiency loss & & $\mathrm{X}$ & 3 & 40 \\
\hline
\end{tabular}

a) A reduction in revenues due to higher forced outage rates.

b) Hot start costs for a $1 \mathrm{GW}$ PC power plant (€/MW installed $\pm 20 \%)$ [134].

c) Hot start costs for a $120 \mathrm{MW}$ NGCC power plant ( $€ / \mathrm{MW}_{\text {installed }} \pm 50 \%$ ) [135].

An overview of reported start-up costs is provided in Table B.2. We base our analysis on the costs reported by Lew et al [Table 5], because they employ the broad cost definition, provide cost figures for all types of starts, and are based on operational data. These costs are based on the lower range of costs, however, and they might be on the low side: Lefton, Vishwathan and DENA report values that are up to six times the reported values [Table B.2]. These high values can be explained by the considerably higher start-up fuel demand (DENA), and the high capital costs. As Troy stated, it is unclear how expensive start-up costs really are [136]. Therefore, a sensitivity analysis will be performed for different levels of start-up costs.

Table B.2: Reported start-up costs in literature in $€^{\prime} \mathbf{M W}_{\text {installed. }}$

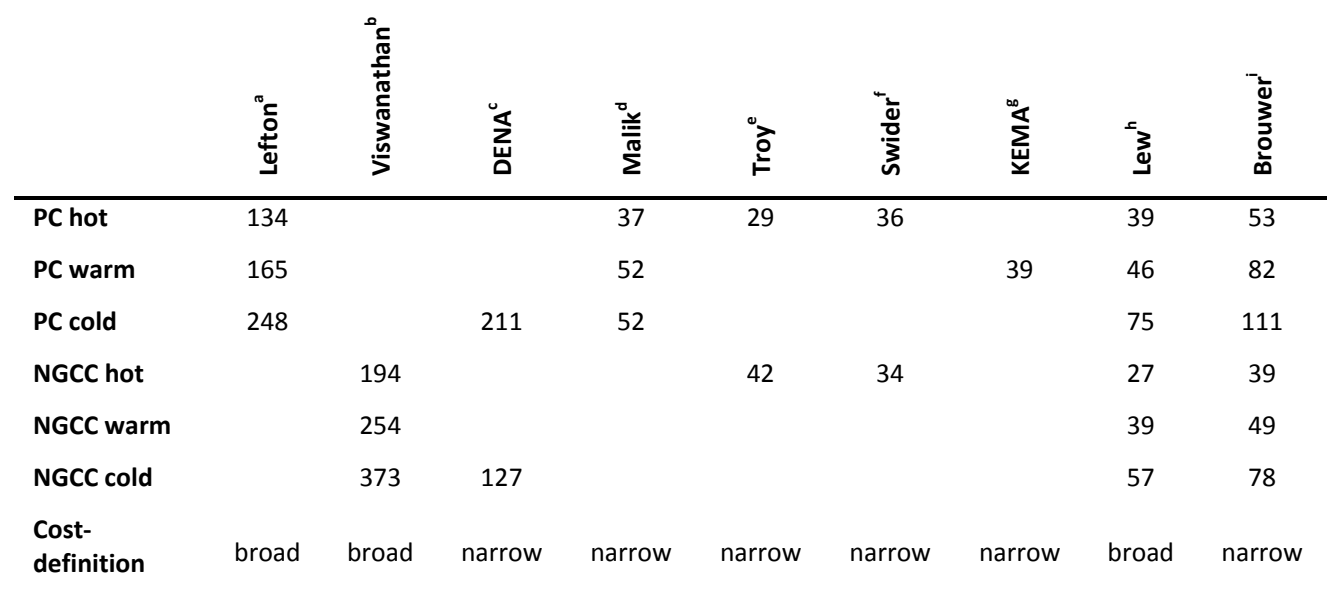

a) Based on a bottom-up analysis. Start costs for a 1 GW PC power plant ( $\left.€ / \mathrm{MW}_{\text {installed }} \pm 20 \%\right)$ [134].

b) Based on a top-down analysis. Start costs for a 120 MW NGCC power plant ( $€ / \mathrm{MW}_{\text {installed }} \pm 50 \%$ ) [135].

c) Based on figures for power plants from 2005. A start-up fuel price of $9 € /$ GJ is assumed for either light fuel oil (PC) or natural gas (NGCC) [138].

d) Based on a function that describes the start-up costs as the boiler start-up costs multiplied by a factor (1-exp(-time off/time constant)) plus the

turbine start-up costs. This was determined in an earlier publication of the same author. [139].

e) Based on input data of the WILMAR model, the origin of which is not specified. It is assumed that these costs apply to hot starts, as they are

published in a table together with hot start startup times [136]. 
f) The source of the figures is not specified, nor the type of start-up cost. For the type of analysis performed it is likely that costs refer to hot start-up costs [140].

g) Based on in-house data of DNV KEMA, assuming a start-up fuel price of $9 € / G J$ [141].

h) Based on a database of 4000 detailed power plant cost studies. Studies performed for U.S. power plants were categorized by power plant type, and a regression analysis was performed. A higher bound and a lower bound fit were determined. Only figures of the lower bound were published, which show a range of $30 \%$ for PC plants ant up to $70 \%$ for NGCC plants [137].

i) Based on a approximation by the authors, where the start-up costs are calculated based on the fuel, $\mathrm{CO}_{2}$, and depreciation costs. Auxiliary power is generated by the unit itself. Start-ups are assumed to be performed with natural gas, at a price of $9 € / \mathrm{GJ}_{\text {, a } \mathrm{CO}}$ price of $10 € / \mathrm{tCO} \mathrm{O}_{2}$ and emissions of $68 \mathrm{~kg} \mathrm{CO}_{2} / \mathrm{GJ}$. The heat requirement of the startup is based that of modern Irish PC and NGCC units [75], which is between the figures reported by

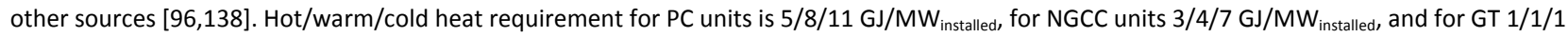

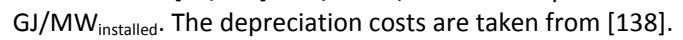

The start-up of a $\mathrm{CO}_{2}$ capture unit will incur all types of start-up costs presented in Table B.2, but these have not been quantified in literature. Cohen assessed the sensitivity of the model outcomes to a range of capture unit start-up costs, and found that the capture unit start-up costs only noticeably affected the model outcomes (a $2.5 \%$ reduction in profit) if they were equal to the start-up costs of a PC power plant [13]. Considering the limited potential for thermal stress and limited complexity of a capture unit, such high costs seem unlikely, so capture unit start-up costs are not included in the model. 


\section{Appendix C: Description of REPOWERS input parameters}

\section{Load and renewable electricity production patterns}

Load and wind/solar PV generation patterns are based on historical time series that are adjusted for future developments, as recommended by [8]. Time series from the year 2011 are used, because its annual wind power production is close to the multi-year average ( $96 \%$ of the 10 -year average, which has a variation of $\pm 15 \%$ ) [76].

Wind power production is calculated based on wind speed measurements, as described in [77]. First, three offshore wind turbine areas and seven onshore areas were defined [Table C.1], for which historical hourly wind speed measurements were obtained [78]. Second, the reported wind speed measurements for a height of 10 meters were converted to a hub height of 80-100 meters using the log law reported by Lackner [79]. Third, the electricity production is determined using two wind-speed/power-output curves: one for onshore [80], and one for offshore turbines $[80,81]$. The resulting capacity factors are $28 \%$ for onshore and $47 \%$ for offshore wind. The offshore capacity factor is in line with the projected factor for the mid-2020s of $45 \%$ by Heptonstall et al. [82].

Table C.1: Regions considered for calculation of wind power production

\begin{tabular}{|c|c|c|c|}
\hline & Area & Share in $2030 \& 2050^{a}$ & KNMI measuring stations ${ }^{e}$ \\
\hline \multirow[t]{3}{*}{ Offshore } & Off the Noord Holland coast & $43 \%$ of offshore ${ }^{b}$ & K13-A, K14-FA-1C, Hoorn-A \\
\hline & Off the Zuid Holland coast & $43 \%$ of offshore ${ }^{b}$ & Euro Platform, P11-B, Goeree LE \\
\hline & North of the Netherlands & $14 \%$ of offshore ${ }^{b}$ & AWG-1, L9-FF-1 \\
\hline \multirow[t]{7}{*}{ Onshore $^{d}$} & Groningen & $11 \%$ of onshore ${ }^{c}$ & Lauwersoog, Nieuw Beerta \\
\hline & Friesland & $18 \%$ of onshore ${ }^{c}$ & Leeuwarden, Stavoren \\
\hline & Flevoland & $31 \%$ of onshore ${ }^{c}$ & Markenesse, Lelystad \\
\hline & Noord Holland & $17 \%$ of onshore ${ }^{c}$ & De Kooy, Schiphol \\
\hline & Zuid Holland & $8 \%$ of onshore ${ }^{c}$ & Rotterdam, Hoek van Holland \\
\hline & Zeeland & $11 \%$ of onshore ${ }^{c}$ & Vlissingen, Wilhelminadorp \\
\hline & Noord-Brabant & $3 \%$ of onshore ${ }^{b}$ & Woensdrecht, Gilze-rijen \\
\hline
\end{tabular}

a) The installed capacities per scenario are shown in Figure 3.

b) Division of offshore capacity is based on the 2030 projections of TenneT and the Basic 2020 scenario of Gibescu et al. [77,83].

c) Division of onshore capacity is based on the current Dutch distribution of onshore wind energy [76].

d) Only 7 provinces are included, as 5 remaining provinces only make up $2.5 \%$ of the total installed capacity. This share will only slightly increase in the future up to $12 \%$

e) The hourly production is calculated based on the average hourly wind speed of the measuring stations per area.

The hourly solar PV power production pattern is constructed by fitting the total annual Dutch solar PV production in 2011 on the hourly average insolation pattern of 11 weather measurement locations across the Netherlands [78].

\section{Reserve size}

Three types of reserves are distinguished in this study: spinning, sub-hourly standing reserves and hourly standing reserves. The reserve size is determined by the inherent uncertainty of the prediction of both load and the generation by intermittent renewable sources. Based on previous findings, reserve sizes are expressed as a percentage of load and intermittent electricity production. For each reserve type, only the provision of reserve capacity is modeled, not the actual generation of reserves. Only upward reserves are presented, because sufficient downwards reserves are available at all times by ramping down units and curtailing wind power. 
Spinning reserves consist of frequency and regulating reserves that have lead times of $<15$ minutes and thus can only be delivered by online units. Units can supply up to $10 \%$ of their capacity as spinning reserves, to ensure that not all spinning reserves are delivered by a couple of units. Wind integration studies show that the effect of higher wind penetration levels on frequency reserves (primary control reserve with an activation time smaller than 30 seconds) is limited, increasing the reserve size by up to $0.8 \%$ of installed wind capacity [8]. The increase in regulating reserves (secondary control reserve with an activation time up to 15 minutes) resulting from wind power is $0-3 \%$ of installed wind power capacity [8]. In this analysis, spinning reserves have a size equal to $1 \%$ of load, plus a maximum of $2.5 \%$ of installed wind and solar PV capacity [8,84]. The reserves are sized dynamically, depending on the expected intermittent power production and are typically around $400 \mathrm{MW}( \pm 200 \mathrm{MW})$.

Standing reserves are assumed to have lead times of $>15$ minutes, and comprise sub-hourly and hourly reserves. Upwards standing reserves can be delivered by offline units as long as their start-up times are shorter than the reserves' lead time. Downward reserves can be delivered by online units and by curtailing intermittent generators. The size of both upward and downward sub-hourly standing reserves is $800 \mathrm{MW}$, plus $6 \%$ of generating intermittent capacity, and the size of hourly standing reserves is $22 \%$ of generating intermittent capacity [85]. Units can provide multiple types of reserves, but every $\mathrm{MW}$ of reserve capacity can only be designated to one type of reserve.

\section{Exchange with neighboring countries}

The power sectors of neighboring countries are modeled based on cost-supply curve projections, in which 16 types of generators are distinguished. Hence, the model does not account for flexibility constraints abroad. Residual demand patterns were constructed by deducting wind and solar PV electricity generation from the projected load per country for every hour. The electricity price of each country is determined by the intersection of the cost-supply curve and the sum of the residual load plus exports. The specifications of foreign power systems are based on a number of sources [Table C.2].

Table C.2: Description of the representation of the power sector of neighboring countries

\begin{tabular}{|c|c|c|}
\hline Input & Description & Sources \\
\hline Load & $\begin{array}{l}\text { Historical hourly load of 2011, with the same annual } \\
\text { increase as the Netherlands }\end{array}$ & {$[86]$} \\
\hline $\begin{array}{l}\text { Electricity generation } \\
\text { capacity per technology }\end{array}$ & $\begin{array}{l}\text { Projections of the PRIMES model, which were adjusted to } \\
\text { match national projections. }{ }^{\text {a }}\end{array}$ & [87-90] \\
\hline $\begin{array}{l}\text { Specifications of thermal } \\
\text { power generators }\end{array}$ & $\begin{array}{l}\text { Projected specifications, corrected for a reduction in } \\
\text { efficiency. }\end{array}$ & [Table 3] \\
\hline Wind power & $\begin{array}{l}\text { Based on hourly production of } 2011 \text { (DE, DK, UK) or wind } \\
\text { measurements (BE). }{ }^{c}\end{array}$ & {$[78,91-93]$} \\
\hline Solar power & $\begin{array}{l}\text { Based on hourly production of } 2011 \text { (DE, DK) or insolation } \\
\text { measurements (UK, BE). }{ }^{c, d}\end{array}$ & {$[78,94,95]$} \\
\hline
\end{tabular}

a) The 2012 PRIMES' Baseline and Reference scenarios were adjusted to reflect the current national goals, as reported in national reports. For example, the PRIMES outcomes were corrected for projected shares of renewables, nuclear and CCS-capacity per country. A summary of installed capacities is provided in Tables C.4-C.7.

b) The efficiency is reduced by $\sim 1$ percentage-point for coal-fired, and $\sim 5$ percentage-points for natural gas fired capacity to account for part-load operation (Figure 2), and 0.8 (coal-fired) / 0.3 (natural gas fired) percentage-points to reflect that mostly draft cooling is used in neighboring countries, rather than once-through cooling. [96,97].

c) No renewable production patterns were available for Belgium for the year 2011, so the RES generation patterns are based on the closest proxy: measurements from the south of the Netherlands.

d) No Danish solar PV generation pattern is available, so it is based on the closest proxy: solar PV generation in the North of Germany

Interconnection capacity is based on the current installed interconnection capacity, which is extended based on shortterm and long-term projections [Table C.3][83,98,99]. In the Baseline scenario, only current expansion plans to Germany are included. In the Stalemate scenario, the interconnection capacity that is currently being planned is also included. In the Global Union and Fuel Shift scenarios, all capacity additions that are suggested in the Tradewind and TenneT studies are also included. It is assumed that $75 \%$ of the net transfer capacity is available during situations of 
large interconnection flows, as a result of loop flows and (forced) outages [100]. A transmission charge of $5 € / \mathrm{MWh}$ is assumed, based on historical values [101].

Table C.3: Current NTC capacity and projected interconnection capacity expansions with neighboring countries

\begin{tabular}{lcccc}
\hline & Current capacity & \multicolumn{2}{c}{ Future expansion of interconnection capacity (year) } \\
\hline (MW) & Baseline (MW) & Stalemate (MW) & $\begin{array}{c}\text { Global Union \& Fuel Shift } \\
(\mathrm{MW})\end{array}$ \\
\hline Germany & $3700^{\mathrm{a}}$ & $1300(2020)$ & $1300(2020)$ & $1300(2020)$ \\
Denmark & 0 & $X$ & $700(2030)$ & $700(2030) \&$ \\
U.K. & 1000 & $X$ & $X$ & $700(2040)$ \\
Belgium & $2300^{\mathrm{a}}$ & $X$ & $X$ & $1000(2030)$ \\
\hline
\end{tabular}

a) Average of both flow directions.

Table C.4 Installed capacity in Germany per scenario (GW)

\begin{tabular}{|c|c|c|c|c|c|c|}
\hline & 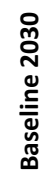 & 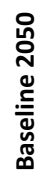 & 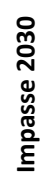 & 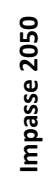 & 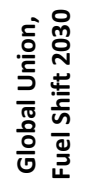 & 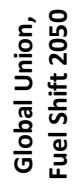 \\
\hline Nuclear & 0 & 0 & 0 & 0 & 0 & 0 \\
\hline Hydro & 5 & 5 & 5 & 5 & 5 & 5 \\
\hline Onshore wind & 48 & 48 & 52 & 66 & 86 & 94 \\
\hline Offshore wind & 11 & 11 & 24 & 29 & 24 & 28 \\
\hline Solar PV & 56 & 56 & 63 & 65 & 63 & 74 \\
\hline Solid fuels & 54 & 73 & 37 & 14 & 18 & 0 \\
\hline Solid fuels+CCS & 0 & 0 & 0 & 9 & 19 & 19 \\
\hline NGCC & 30 & 51 & 49 & 76 & 28 & 0 \\
\hline $\mathrm{NGCC}+\mathrm{CCS}$ & 0 & 0 & 0 & 0 & 32 & 76 \\
\hline \multirow[t]{2}{*}{ Biomass } & 9 & 10 & 9 & 11 & 9 & 11 \\
\hline & 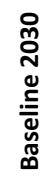 & 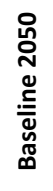 & 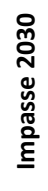 & 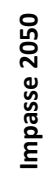 & 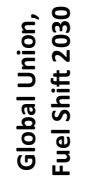 & 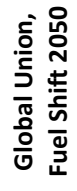 \\
\hline Nuclear & 0 & 0 & 0 & 0 & 0 & 0 \\
\hline Hydro & 0 & 0 & 0 & 0 & 0 & 0 \\
\hline Onshore wind & 3 & 4 & 4 & 5 & 5 & 8 \\
\hline Offshore wind & 1 & 1 & 2 & 5 & 3 & 6 \\
\hline Solar PV & 3 & 5 & 4 & 7 & 6 & 10 \\
\hline Solid fuels & 5 & 7 & 0 & 0 & 0 & 0 \\
\hline Solid fuels+CCS & 0 & 0 & 0 & 0 & 0 & 0 \\
\hline NGCC & 11 & 14 & 14 & 16 & 14 & 2 \\
\hline $\mathrm{NGCC}+\mathrm{CCS}$ & 0 & 0 & 0 & 7 & 0 & 15 \\
\hline Biomass & 1 & 2 & 2 & 2 & 2 & 2 \\
\hline
\end{tabular}




\begin{tabular}{|c|c|c|c|c|c|c|}
\hline & 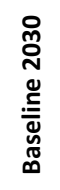 & 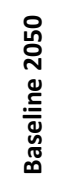 & 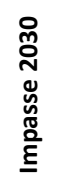 & 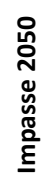 & 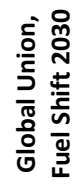 & 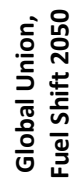 \\
\hline Nuclear & 11 & 14 & 8 & 10 & 16 & 19 \\
\hline Hydro & 2 & 2 & 2 & 2 & 2 & 2 \\
\hline Onshore wind & 18 & 27 & 16 & 21 & 13 & 13 \\
\hline Offshore wind & 8 & 9 & 15 & 20 & 37 & 37 \\
\hline Solar PV & 4 & 4 & 5 & 5 & 6 & 7 \\
\hline Solid fuels & 9 & 8 & 0 & 0 & 0 & 0 \\
\hline Solid fuels+CCS & 0 & 0 & 5 & 0 & 5 & 0 \\
\hline NGCC & 52 & 57 & 47 & 49 & 50 & 16 \\
\hline $\mathrm{NGCC}+\mathrm{CCS}$ & 0 & 0 & 6 & 12 & 7 & 66 \\
\hline Biomass & 3 & 4 & 3 & 4 & 3 & 4 \\
\hline
\end{tabular}

Table C.7: Installed capacity in Denmark per scenario (GW)

\begin{tabular}{|c|c|c|c|c|c|c|}
\hline & 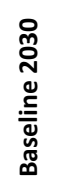 & 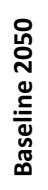 & 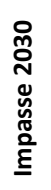 & 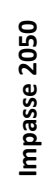 & 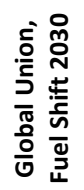 & 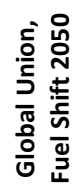 \\
\hline Nuclear & 0 & 0 & 0 & 0 & 0 & 0 \\
\hline Hydro & 0 & 0 & 0 & 0 & 0 & 0 \\
\hline Onshore wind & 7 & 7 & 7 & 10 & 7 & 10 \\
\hline Offshore wind & 2 & 2 & 2 & 2 & 3 & 5 \\
\hline Solar PV & 1 & 1 & 1 & 1 & 1 & 1 \\
\hline Solid fuels & 3 & 2 & 1 & 0 & 1 & 0 \\
\hline Solid fuels+CCS & 0 & 0 & 1 & 1 & 0 & 0 \\
\hline NGCC & 5 & 5 & 5 & 5 & 2 & 0 \\
\hline $\mathrm{NGCC}+\mathrm{CCS}$ & 0 & 0 & 0 & 0 & 5 & 6 \\
\hline Biomass & 1 & 2 & 1 & 2 & 1 & 2 \\
\hline
\end{tabular}




\section{References}

[1] EC. A roadmap for moving to a competitive low carbon economy in 2050. Brussels: European Commission; 2011.

[2] EC. A policy framework for climate and energy in the period from 2020 to 2030 - COM(2014) 15. Brussels: European Commission; 2014.

[3] ECF. Roadmap 2050 - Volume 1 technical analysis. Brussels: 2010.

[4] EC. Energy Roadmap 2050 - COM(2011) 885/2. European Commission. Brussels: 2011.

[5] OECD/IEA. World Energy Outlook 2012. Paris: 2012.

[6] Eurelectric. Flexible generation : Backing up renewables. Report D/2011/12.105/47. Brussels: 2011.

[7] IEA. Energy Technology Perspectives 2012. Paris: International Energy Agency; 2012.

[8] Brouwer AS, Broek M van den, Seebregts A, Faaij A. Impacts of large-scale electricity generation by intermittent renewable energy sources on the electricity system, and how these can be evaluated. Renew Sustain Energy Rev 2014;33:443-66.

[9] IPCC. IPCC Special Report on Renewable Energy Sources and Climate Change Mitigation. Cambridge: Cambridge University Press; 2011.

[10] OECD/IEA. Harnessing variable renewables. A Guide to the Balancing Challenge. Paris: International Energy Agency; 2011.

[11] Bertsch J, Growitsch C, Lorenczik S, Nagl S. Flexibility options in European electricity markets in high RES-E scenarios - Study on behalf of the International Energy Agency. Energiewirtschaftliches Institut an Der Universität Zu Köln (EWI). Cologne, Germany: 2012.

[12] McCoy S, Bertsch J, Growitsch C, Lorenczik S, Nagl S, Volk D, et al. The role of CCS in power systems with high levels of renewables penetration 2013.

[13] Cohen S. A Techno-economic Plant- and Grid-Level Assessment of Flexible CO 2 Capture. PhD dissertation. The University of Texas at Austin, 2012.

[14] Hundt M, Barth R, Sun N, Brand H, Voß A. Herausforderungen eines Elektrizitätsversorgungssystems mit hohen Anteilen erneuerbarer Energien. Institut Für Energiewirtschaft Und Rationelle Energieanwendung, Universität Stuttgart. Stuttgart: 2010.

[15] Seebregts A, van Deurzen J. Carbon capture \& storage in power generation and wind energy: Flexibility and reliability issues in scenarios for Northwest Europe. Energy Procedia 2011;4:5877-88.

[16] Ludig S, Haller M, Bauer N. Tackling long-term climate change together: The case of flexible CCS and fluctuating renewable energy. Energy Procedia 2011;4:2580-7.

[17] PBL/ECN. Naar een schone economie in 2050: routes verkend. Den Haag: 2011.

[18] Seebregts A, Goldstein G, Smekens K. Energy/environmental modeling with the MARKAL family of models. Options Res Proc 2001 2002;2001:75-82. 
[19] IEA ETSAP. Description of MARKAL. Http://www.iea-etsap.org/web/Markal.asp. Last Accessed 2901-2014: 2014.

[20] Broek, van den M, Veenendaal P, Koutstaal P, Turkenburg W, Faaij A. Impact of international climate policies on $\mathrm{CO} 2$ capture and storage deployment: Illustrated in the Dutch energy system. Energy Policy 2011;39:2000-19.

[21] Vliet, van O, Broek, van den $M$, Turkenburg W, Faaij A. Combining hybrid cars and synthetic fuels with electricity generation and carbon capture and storage. Energy Policy 2011;39:248-68.

[22] Brouwer AS, Kuramochi T, van den Broek M, Faaij A. Fulfilling the electricity demand of electric vehicles in the long term future: An evaluation of centralized and decentralized power supply systems. Appl Energy 2013;107:33-51.

[23] ECN. Tools - Modelling Systems - REPOWERS. Http://www.ecn.nl/units/ps/models-andTools/repowers/. Last Accessed: 14-12-2013: 2012.

[24] Deane JP, Chiodi A, Gargiulo M, Ó Gallachóir BP. Soft-linking of a power systems model to an energy systems model. Energy 2012;42:303-12.

[25] Vuorinen A. Planning of Optimal Power Systems. Espoo, Finland: Okoenergo Oy; 2009.

[26] Verdonk M, Wetzels W. Referentieraming Energie en Emissies: Actualisatie 2012. PBL and ECN; 2012.

[27] Metz B, Davidson OR, Bosch PR, Dave R, Meyer LA, (eds). Climate Change 2007: Mitigation. Contribution of Working Group III to the Fourth Assessment Report of the In tergovernmental Panel on Climate Change. Cambridge University Press, Cambridge, United Kingdom and New York, NY, USA.: 2007.

[28] Eurostat. ECU/EUR exchange rates versus national currencies 2013.

[29] IHS. IHS CERA Power Capital Costs Index (PCCI). Http://www.ihs.com/info/cera/ihsindexes/index.aspx. Last Accessed: 20-03-2014. Englewood, Colorado.: 2013.

[30] Meerman JC, Ramírez a., Turkenburg WC, Faaij a. PC. Performance of simulated flexible integrated gasification polygeneration facilities, Part B: Economic evaluation. Renew Sustain Energy Rev 2012;16:6083-102.

[31] ZEP. The Costs of CO 2 Capture, Transport and Storage - Post-demonstration CCS in the EU. Brussels: 2011.

[32] GCCSI. Economic Assessment Carbon Capture and Storage Technologies - 2011 Update. 2011.

[33] OECD/IEA. Projected Costs of Generating Electricity 2010. Paris: OECD Publishing; 2010.

[34] EPRI. Program on Technology Innovation: Integrated Generation Technology Options. Palo Alto, California, US: 2011.

[35] NETL. Current and Future Technologies for Power Generation with Post- Combustion Carbon Capture Final Report. 2012. 
[36] NETL. Cost and Performance Baseline for Fossil Energy Plants Volume 1 : Bituminous Coal and Natural Gas to Electricity. 2010.

[37] Knoope MMJ, Meerman JC, Ramírez A, Faaij APC. Future technological and economic performance of IGCC and FT production facilities with and without CO 2 capture : combining component based learning curve and bottom-up analysis . Int J Greenh Gas Control 2013.

[38] Kuramochi T, Ramírez A, Turkenburg W, Faaij A. Techno-economic prospects for CO2 capture from distributed energy systems. Renew Sustain Energy Rev 2013;19:328-47.

[39] Kuramochi T, Faaij A, Ramírez A, Turkenburg W. Prospects for cost-effective post-combustion CO2 capture from industrial CHPs. Int J Greenh Gas Control 2010;4:511-24.

[40] Kuramochi T, Turkenburg W, Faaij A. Competitiveness of $\mathrm{CO} 2$ capture from an industrial solid oxide fuel cell combined heat and power system in the early stage of market introduction. Fuel 2011;90:958-73.

[41] Telgte P Ter. Prospects of capture and geological storage of $\mathrm{CO} 2$ from CHP plants in the Netherlands. MSc Thesis. Utrecht, The Netherlands: 2012.

[42] Lako P. IEA ETSAP - Technology Brief E04 - Combined Heat and Power. 2010.

[43] Hers JS, Wetzels W, Seebregts AJ, Welle A Van Der. Onrendabele top berekeningen voor nieuw WKK-vermogen 2008. Petten: 2008.

[44] IEAGHG. CO2 Capture from Medium Scale Combustion - 2007/7. Cheltenham, UK: 2007.

[45] CBS. Elektriciteitsbalans; aanbod en verbruik. http://statline.cbs.nl/StatWeb/?LA=nl. Last Accessed: 20-03-2014. Heerlen, The Netherlands: 2013.

[46] TenneT. Exporteer data Consumptie. Http://energieinfo.tennet.org/. Last Accessed on 20-03-2014. Arnhem, The Netherlands: 2013.

[47] Ummels B. Power System Operation with Large-Scale Wind Power in Liberalised Environments. PhD Dissertation. Delft University, 2009.

[48] ECN. MONITweb. Http://monitweb.energie.nl/.aspx. Last Accessed on 20-03-2014. Energy Reserach Centre of The Netherlands Petten, The Netherlands: 2014.

[49] ECN. WKK Basislijst (confidential). Energy Reserach Centre of The Netherlands. Petten, The Netherlands: 2013.

[50] NEN. NPR 2917. http://www.nen.nl/web/Normshop/Norm/NPR-2917A22010-v.2.2-NI.htm. Last Accessed on 20-03-2014. Delft: NEN; 2010.

[51] Cogen Projects. WKK in Het Nieuwe Telen WKK in Het Nieuwe Telen Een analyse van de rentabiliteit. 2010.

[52] Jeschke R, Henning B, Schreier W. Flexibility through highly- efficient technology. VGB PowerTech 2012:5.

[53] Dijkema G, Lukszo Z, Verkooijen A, Vries L de, Weijnen M. De regelbaarheid van elektriciteitscentrales. Delft University. Delft, The Netherlands: 2009. 
[54] IEAGHG. Operating Flexibility of Power Plants with CCS, 2012/6. Cheltenham, UK: 2012.

[55] Klobasa M, Erge T, Wille-haussmann B. Integration von Windenergie in ein zukünftiges Energiesystem unterstützt durch Lastmanagement. Report 0327577. Fraunhofer Institut Für System- Und Innovationsforschung. Karlsruhe: 2009.

[56] Balling L. Flexible future for combined cycle. Mod Power Syst 2010:61-5.

[57] Isles J. Prospects for lower cost and more efficient IGCC power. Gas Turbine World 2012:4.

[58] Stevens M, Hummel F, Jakoby R, Eppler V, Ruchti C, Power A. Increased operational flexibility from the latest GT26 ( 2011 ) upgrade. PowerGen Eur. 2012, Cologne, Germany: PennWell Corporation; 2012, p. 20.

[59] NETL. Impact of Load Following on Power Plant Cost and Performance : Literature Review and Industry Interviews. 2012.

[60] Lew D, Brinkman G, Ibanez E, Florita A, Heaney M, Hodge B, et al. The Western Wind and Solar Integration Study Phase 2. Report NREL/TP-5500-55588. NREL. Golden, Colorado: 2013.

[61] Meerman JC, Ramírez A, Turkenburg WC, Faaij APC. Performance of simulated flexible integrated gasification polygeneration facilities. Part A: A technical-energetic assessment. Renew Sustain Energy Rev 2011;15:2563-87.

[62] Linnenberg S, Oexmann J, Kather A. Design Considerations of Post-Combustion Post Combustion CO 2 Capture Process during Part Load Operation of Coal-Fired Power Plants. 12th Int. post Combust. capture Netw. Meet., 2009.

[63] Sakai K, Morita S, Sato T. State-of-the-art Technologies for the $1,000-\mathrm{MW} 24.5-\mathrm{MPa} / 600^{\circ} \mathrm{C} / 600^{\circ} \mathrm{C}$ Coal-fired Boiler. Hitachi Rev 1999;48:273-6.

[64] OECD/IEA. Power Generation from Coal - Measuring and Reporting Efficiency Performance and CO2 Emissions. International Energy Agency. Paris: 2010.

[65] Roeder V, Hasenbein C, Kather A. Evaluation and Comparison of the Part Load Behaviour of the CO 2 Capture Technologies Oxyfuel and Post-Combustion 2013;00.

[66] Breeze P. Efficiency versus flexibility: Advances in gas turbine technology. Power Energineering Int 2011:1-7.

[67] Probert T. Fast starts and flexibility - Let the gas turbine battle commence. Power Energineering Int 2011:8.

[68] IEAGHG. CO2 Capture at Gas Fired Power Plants, 2012/8. Cheltenham, UK: 2012.

[69] MITEI. MIT Energy Initiative Symposium on Managing Large-Scale Penetration of Intermittent Renewables. April 20, 2011. Cambridge, Massachusetts.: 2011.

[70] Kim T. Comparative analysis on the part load performance of combined cycle plants considering design performance and power control strategy. Energy 2004;29:71-85. 
[71] Bruynooghe C, Eriksson A, Fulli G. Load-following operating mode at Nuclear Power Plants (NPPs) and incidence on Operation and Maintenance $(\mathrm{O} \& \mathrm{M})$ costs . Compatibility with wind power variability. Luxembourgh: 2010.

[72] NERC. Generating Unit Statistical Brochure - 2006-2010 Generating Availability Data System (GADS). 2011.

[73] ENTSO-E. System Adequacy Forecast 2011 - 2025. Brussels: 2011.

[74] EEX Transparency Platform. Unscheduled non-usabilities of generating units of $\geq 100 \mathrm{MW}$. Http://www.transparency.eex.com/en/. Last Accessed on 20-03-2014. Leipzig, Germany: 2013.

[75] Meibom P, Barth R, Brand H, Hasche B, Swider D, Ravn H, et al. All Islands Grid Study, workstream 2B. Risoe National Laboratory. Roskilde: 2008.

[76] CBS. Windenergie; elektriciteitsproductie, capaciteit en windaanbod per maand. Statline 2013.

[77] Gibescu M, Brand AJ, Kling WL. Estimation of Variability and Predictability of Large-scale Wind Energy in The Netherlands 2009:241-60.

[78] KNMI. Uurgegevens van het weer in Nederland. Http://www.knmi.nl/klimatologie/uurgegevens/. Last Accessed on 20-03-2014. De Bilt, The Netherlands: 2013.

[79] Lackner M a., Rogers AL, Manwell JF, McGowan JG. A new method for improved hub height mean wind speed estimates using short-term hub height data. Renew Energy 2010;35:2340-7.

[80] J. R. McLean. Equivalent Wind Power Curves - Tradewind WP 2.6. 2008.

[81] EC. IRENE-40 Annex 4 . 2 - Large Scale Integration of Intermittent Electricity Generation. Brussels: 2011.

[82] Heptonstall P, Gross R, Greenacre P, Cockerill T. The cost of offshore wind: Understanding the past and projecting the future. Energy Policy 2012;41:815-21.

[83] TenneT. Visie2030. TenneT TSO. Arnhem, The Netherlands: 2010.

[84] NERC. Balancing and Frequency Control. NERC Resources Subcommittee. Princeton, NJ.: 2011.

[85] De Boer WW, Van der Veen W. Balancing with $6000 \mathrm{MW}$ off shore Wind Energy in The Netherlands; an analysis of the flexibility of production. 8th Int. Work. Large-Scale Integr. Wind Power into Power Syst. as well as Transm. Networks Offshore Wind Farms, Bremen: 2009.

[86] ENTSO-E. Hourly load values of ENTSO-E countries. Https://www.entsoe.eu/data/dataPortal/consumption/. Last Accessed on 20-03-2014. Brussels.: 2013.

[87] National Grid. UK Future Energy Scenarios. Warwick, UK: 2011.

[88] Feix O, Obermann R, Strecker M, Brötel A. Netzentwicklungsplan Strom 2013. 2013.

[89] Dufresne L, Fauconnier M, Ruyck J de. Groep gemix - Welke is de ideale energiemix voor België tegen 2020 en 2030 ? Brussels: 2012. 
[90] EC. EU Energy, Transport and GHG Emissions Trends to 2050. Reference Scenario 2013. European Commission. Brussels: 2013.

[91] EEX Transparency Platform. Actual wind power generation. Http://www.transparency.eex.com/en/. Last Accessed on 20-03-2014. Leipzig, Germany: 2013.

[92] Energinet.dk. Wind power production in Denmark 2013.

[93] Elexon. Historic Generation by Fuel Type. Www.elexonportal.co.uk/historicgenerationbyfueltype. Last Accessed 20-03-2014. London: 2013.

[94] UK Meteorological Office. Met Office Integrated Data Archive System (MIDAS) Land and Marine Surface Stations Data (1853-current) 2013.

[95] EEX Transparency Platform. Actual solar power generation. Http://www.transparency.eex.com/en/. Last Accessed on 20-03-2014. Leipzig, Germany: 2013.

[96] Spliethoff H. Power Generation from Solid Fuels. Berlin, Heidelberg: Springer; 2010.

[97] EPA. Technical Development Document for the Final Regulations Addressing Cooling Water Intake Structures for New Facilities. Report EPA-821-R-01-036. United States Environmental Protection Agency. Washington D.C.: 2001.

[98] Korpås M, Warland L, Tande JO, Uhlen K, Boer J, Groeman F, et al. TradeWind WP6.1 - Assessment of increasing capacity on selected transmission corridors. 2008.

[99] ENTSO-E. 10-Year Network Development Plan 2012. Brussels: 2012.

[100] TenneT. Rapport Monitoring Leveringszekerheid 2011-2027 - RGE2012-115. Arnhem: 2012.

[101] TenneT. Auction results. http://energieinfo.tennet.org/Connection/AuctionResults.aspx Last Accessed 20-03-2014. Arnhem, The Netherlands: 2013.

[102] E.ON. Kingsnorth Carbon Dioxide Capture and Storage Demonstration Project FEED Study. 2011.

[103] Klinkby L, Nielsen CM, Krogh E, Smith IE, Palm B, Bernstone C. Simulating rapidly fluctuating CO2 flow into the Vedsted CO2 pipeline, injection well and reservoir. Energy Procedia 2011;4:4291-8.

[104] Veen W, Moldovan N, Benz E, Hewicker C. Nut en Noodzaak van Grootschalige Energieopslag in Nederland. KEMA. Arnhem: 2010.

[105] IEAGHG. Potential for Biomass and Carbon Capture and Storage 2011/06. Cheltenham: 2011.

[106] ZEP. Biomass with CO 2 Capture and Storage ( Bio-CCS ) The way forward for Europe. Brussels: 2013.

[107] Luckow P, Wise MA, Dooley JJ, Kim SH. Large-scale utilization of biomass energy and carbon dioxide capture and storage in the transport and electricity sectors under stringent $\mathrm{CO} 2$ concentration limit scenarios. Int J Greenh Gas Control 2010;4:865-77.

[108] Batidzirai B, Hilst F Van Der, Meerman H, Junginger MH, Faaij APC. Optimization potential of biomass supply chains with torrefaction technology. Biofuels, Bioprod Biorefining 2013:5-7. 
[109] Smeets E, Faaij a, Lewandowski I, Turkenburg W. A bottom-up assessment and review of global bioenergy potentials to 2050. Prog Energy Combust Sci 2007;33:56-106.

[110] Dornburg V, Vuuren D van, Ven G van de, Langeveld H, Meeusen M, Banse M, et al. Bioenergy revisited: Key factors in global potentials of bioenergy. Energy Environ Sci 2010;3:253.

[111] Batidzirai B, Mignot a. PR, Schakel WB, Junginger HM, Faaij a. PC. Biomass torrefaction technology: Techno-economic status and future prospects. Energy 2013;62:196-214.

[112] Virmani S, Adrian EC, Imhof K, Mukherjee S. Implementation of a Lagrangian relaxation based unit commitment problem. IEEE Trans Power Syst 1989;4:1373-80.

[113] Wood W. Spinning Reserve Constrained Static and Dynamic Economic Dispatch. IEEE Trans Power Appar Syst 1982;PAS-101:381-8.

[114] Wang SJ, Shahidehpour SM, Kirschen DS, Mokhtari S, Irisarri GD. Short-term generation scheduling with transmission and environmental constraints using an augmented Lagrangian relaxation. IEEE Trans Power Syst 1995;10:1294-301.

[115] Saygin D, Patel MK, Worrell E, Tam C, Gielen DJ. Potential of best practice technology to improve energy efficiency in the global chemical and petrochemical sector. Energy 2011;36:5779-90.

[116] Boer-Meulman P, Burgt JJA van der, Hafkamp PJM, Hunik R, Kokmeijer E, Kolokathis C, et al. Effect of scenarios and alternatives for electric vehicles and heat pump implementation on grid reliability, sustainability and socio-economy - WP 3 Report nr . 10-4193. Den Haag: 2010.

[117] OECD/NEA. T echnical and Economic Aspects of Load Following with Nuclear Power Plants. Issy-LesMoulineaux, France: 2011.

[118] Kral R, Wittchow E. Steam Generators for the Next Generation of Power Plants. Aspects of Design and Operating Performance. VGB PowerTech 1999:12.

[119] Richardson M, Kidera Y, Shimogori Y. Supercritical Boiler Technology Matures. Hitachi America. New York, USA: 2004.

[120] Vogt J, Schaaf T, Mohr W, Helbig K. Flexibility improvement of the steam turbine of Conventional or CCPP. PowerGen Eur. 2013, Vienna: PennWell Corporation; 2013, p. 21.

[121] EU. DIRECTIVE 2001/80/EC on the limitation of emissions of certain pollutants into the air from large combustion plants. Brussels: European Union; 2002.

[122] Fischer WJ, Nag P. H-Class High Performance Siemens Gas Turbine SGT-8000H series. Power-Gen Int. 2011, Las Vegas, U.S.: PennWell Corporation; 2011, p. 10.

[123] Black \& Veatch. Cost Report - Cost and Performance Data for Power Generation Technologies. 2012.

[124] Cziesla F, Bewerunge J, Senzel A. Lünen - State-of-the-Art Ultra Supercritical Steam Power Plant Under Construction. PowerGen Eur. 2009, 2009, p. 21.

[125] Brasington RD, Herzog HJ. Integration and operation of post-combustion capture system on coalfired power generation: load following and peak power. MIT, 2012. 
[126] Lawal A, Wang M, Stephenson P, Yeung H. Dynamic modelling of $\mathrm{CO} 2$ absorption for post combustion capture in coal-fired power plants. Fuel 2009;88:2455-62.

[127] Kvamsdal HM, Jakobsen JP, Hoff $\mathrm{K}$ a. Dynamic modeling and simulation of a $\mathrm{CO} 2$ absorber column for post-combustion CO2 capture. Chem Eng Process Process Intensif 2009;48:135-44.

[128] Ziaii S, Cohen S, Rochelle GT, Edgar TF, Webber ME. Dynamic operation of amine scrubbing in response to electricity demand and pricing. Energy Procedia 2009;1:4047-53.

[129] Quinkertz R, Ulma A, Gobrecht E, Wechsung M. USC Steam Turbine technology for maximum efficiency and operational flexibility. PowerGen Asia 2008, 2008, p. 17.

[130] Black \& Veatch. Supplementary study of generating alternatives for Deerhaven generating station Project Number 137196. Jacksonville, USA: 2004.

[131] Balling L. Fast cycling and rapid start-up: new generation of plants. Mod Power Syst 2011:35-41.

[132] GE Energy. LS2100 Static Starter Product Description. Salem, USA: 2002.

[133] Chalmers $\mathrm{H}$. Flexible operation of coal-fired power plants with post-combustion capture of carbon dioxide Submitted for the Degree of Doctor of Philosophy in Environmental Strategy Centre of Environmental Strategy Faculty of Engineering and Physical Sciences. University of Essex, 2010.

[134] Lefton S, Hilleman D. The Cost of Cycling Coal Fired Power Plants. Coal Power Magazine Winter 2006.: 2006 .

[135] Viswanathan V, Gray D. Damage to Power Plants Due to Cycling. EPRI. Palo Alto, USA: 2001.

[136] Troy N, Denny E, O'Malley M. The relationship between base-load generation, start-up costs and generation cycling. 28th USAEE/IAEE North Am. Conf., New Orleans, US: International Association for Energy Economics; 2008, p. 1-15.

[137] Lew D, Brinkman G, Kumar N, Besuner P, Agan D, Lefton S. Impacts of Wind and Solar on FossilFueled Generators Preprint. IEEE Power Energy Soc. Gen. Meet., San Diego, California: 2012.

[138] Deutschen Energie-Agentur GmbH. Energiewirtschaftliche Planung für die Netzintegraation von Windenergie in Deutschland an Land und Offshore bis zum Jahr 2020. Deutschen Energie-Agentur GmbH. Cologne: 2005.

[139] Malik AS, Cory BJ. Integrated resource planning with consideration of dynamic costs of thermal units. Electr Power Syst Res 1999;51:123-30.

[140] Swider DJ, Weber C. An electricity market model to estimate the marginal value of wind in an adapting system. 2006 IEEE Power Eng Soc Gen Meet 2006:8 pp.

[141] Wijk, van der P, Brouwer AS, Broek, van den M, Slot T, Stienstra G, Veen W van der, et al. Benefits of coal-fired power plant with flexible CCS in a future northwest European power system with large scale wind power n.d. 